University of Wollongong

Research Online

Faculty of Engineering and Information

Faculty of Engineering and Information

Sciences - Papers: Part B

Sciences

2018

Laboratory evaluation of buried high-density polyethylene pipes subjected to localized ground subsidence

Min Zhou

Southeast University

Fei Wang

RTE Technologies

Yan Jun Du

Southeast University

Martin D. Liu

University of Wollongong, martindl@uow.edu.au

Follow this and additional works at: https://ro.uow.edu.au/eispapers1

Part of the Engineering Commons, and the Science and Technology Studies Commons

Research Online is the open access institutional repository for the University of Wollongong. For further information contact the UOW Library: research-pubs@uow.edu.au 


\title{
Laboratory evaluation of buried high-density polyethylene pipes subjected to localized ground subsidence
}

\author{
Abstract \\ The serviceability loss of buried high-density polyethylene (HDPE) double-wall corrugated pipes caused \\ by localized ground subsidence has been reported all over the world. Beam-on-nonlinear spring model is \\ widely used to analyze the structural responses of buried pipes to the localized ground subsidence \\ underneath the pipe. However, the pipe-soil separation is not considered by the beam-on-nonlinear spring \\ model which assumes bonded interaction between the pipe and soil. This is because the spring stiffness \\ could not be assigned as zero. The bonded interaction between pipe and soil is not able to capture the \\ pipe behavior and characteristics of load distribution around the pipe when pipe-soil separation occurs. \\ This study presents a series of large-scale model tests aiming to investigate the performance of buried \\ HDPE double-wall corrugated pipes subjected to the localized ground subsidence. Movable plates \\ installed at the bottom of the model test box are lowered down to simulate the localized ground \\ subsidence. Earth pressures, pipe vertical displacements, and settlements at the backfill surface are \\ monitored. For comparison purpose, free field condition (i.e., without pipe) is also tested. The test results \\ demonstrate that soil settlement troughs above buried pipes are shallower and wider than those at the \\ same elevation in the free field condition. Earth pressures at the top of the pipe are found to increase due \\ to the negative soil arching, i.e., earth pressure is greater than the overburden pressure. It is suggested \\ that three-dimensional soil arching, i.e., soil arching effects in both the transverse and longitudinal \\ directions of the tested pipe, should be considered in calculating the earth pressures at the pipe top. The \\ pipe-soil separation is substantiated by the observation that earth pressure measured at the bottom of \\ the pipe is zero. Finally, empirical equations are proposed to correlate the volume of pipe displacement \\ profile with the volume of settlement trough at the backfill surface to facilitate evaluation of the \\ performance of the pipes subjected to the localized land subsidence. \\ Disciplines \\ Engineering | Science and Technology Studies
}

\section{Publication Details}

Zhou, M., Wang, F., Du, Y. \& Liu, M. D. (2018). Laboratory evaluation of buried high-density polyethylene pipes subjected to localized ground subsidence. Acta Geotechnica, Online First 1-19.

This journal article is available at Research Online: https://ro.uow.edu.au/eispapers1/1721 
Min Zhou

Ph.D. Student, Institute of Geotechnical Engineering, Southeast University, Nanjing, Jiangsu, China, 210096; Email: 230139499@seu.edu.cn

Fei Wang*, PhD

Associate Professor, Institute of Geotechnical Engineering, Southeast University, Nanjing, Jiangsu, China, 210096; Email: feiwangseu@ gmail.com (* Corresponding author)

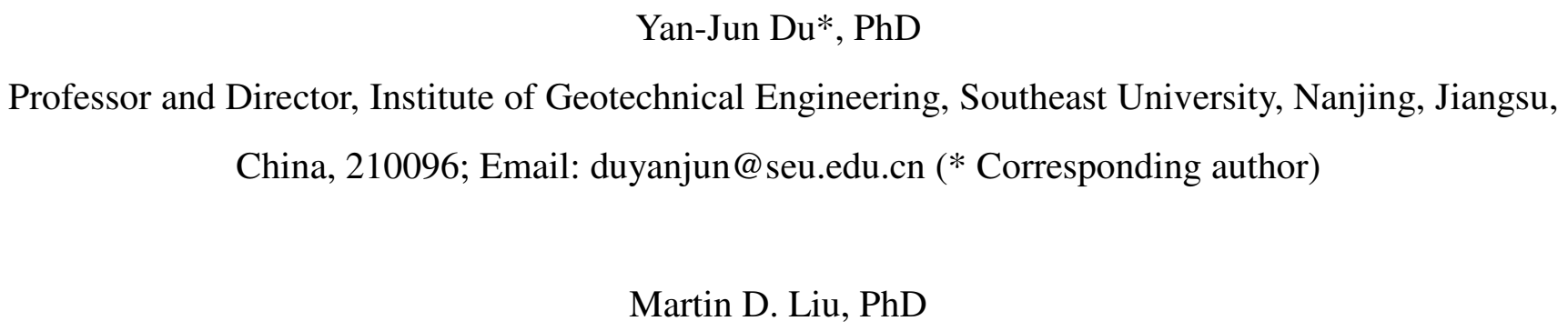

Professor and Director, Institute of Geotechnical Engineering, Southeast University, Nanjing, Jiangsu, China, 210096; Email: duyanjun@ seu.edu.cn (* Corresponding author)

Martin D. Liu, PhD

Senior Lecturer, Faculty of Engineering and Information Sciences, University of Wollongong. E-mail: martindl@uow.edu.au

Full Paper Submitted to Geotextiles and Geomembranes

Tables: 5

Figures: 21

Words in Text: 6848, excluding Abstract and References list 
Abstract: The serviceability loss of High Density PolyEthylene (HDPE) double-wall corrugated pipes caused by localized ground subsidence has been reported all over the world. Theory of beams on Winkler elastic foundation is commonly used to analyze structural responses of buried pipes subjected to ground subsidence. However, the theory of beams on Winkler elastic foundation assumes that the displacement of buried pipes exactly matches the soil settlement trough (i.e., the displacement of pipe is equal to the soil settlement underneath the pipe). This assumption is not able to present the pipe behavior and load distribution around the pipe when pipe-soil separation occurs at the pipe-soil interface by which the pipe response (i.e., internal stresses and strains) would be overestimated. A series of large-scale model tests are carried out to investigate the performance of HDPE double-wall corrugated pipes subjected to localized ground subsidence. Movable plates installed at the bottom of the box are lowered down to simulate localized ground subsidence. Earth pressures, pipe vertical displacements, and surface settlements of the backfill are measured. For comparative studies, free field soil (i.e., without pipe) is also tested. The test results demonstrate that soil settlement troughs for buried pipes have shallower but wider shapes than those of the free field soil. The vertical displacements of the pipe are smaller than those in the free field soil. Based on the observation that the earth pressures at the top of the pipe increase because of negative soil arching (i.e., earth pressure is greater than overburden pressure) at the top of the pipe, it is suggested that three-dimensional soil arching effect should be considered in accurately modeling the earth pressures at the pipe top. It is also observed that the earth pressures at the bottom of pipes have been reduced to zero during the forming of the ground subsidence, which confirms the occurrence of the pipe-soil separation. The widely used theory of beams on Winkler elastic foundation in buried pipe design, assuming no separation between soil and pipe, will induce errors for buried pipes subjected to ground 
54 subsidence. Finally, empirical equations are proposed to correlate the volume of pipe displacement profile with the volume of settlement trough at the backfill surface to facilitate the estimation of pipe performance in practice.

Key words: large-scale physical model test; Localized ground subsidence; HDPE pipe; Three-dimensional soil arching.

\section{Introduction}

High density polyethylene (HDPE) double-wall corrugated pipes have been widely used in HDPE double-wall corrugated pipes make up of more than $50 \%$ of all urban drainage pipelines in China (Wu 2014). It is found that some buried HDPE pipes are affected by localized ground subsidence occurred in many cities due to groundwater pumping (Shen and Xu 2011; Xu et al., 2012, 2016) or urban construction (Han et al. 2015; Shen et al, 2016; Wu et al., 2016). For examples, sewer pipelines are damaged by tunneling-induced ground subsidence in Zhengzhou, China (Zhou 2009). Nine people are injured with a massive traffic jam. The ground subsidence induced by irregular underground construction causes the destruction of water-supply HDPE pipelines in Shanghai China

69 (Luo 2015). Three types of additional stresses may act on pipes during localized ground subsidence 70 (e.g., Liu and O'Rourke 1997; Vorster 2005; Gantes and Bouckovalas 2013; Han et al. 2013; Shen et al. 2014; Kouretzis et al. 2015): (1) flexural stress caused by the loss of support at the pipe invert level. Consequently earth pressure at the top of the pipe is elevated due to negative soil arching (i.e.,

73 load on pipe is greater than the overburden stress); (2) shear stress at the pipe-soil interface in the 74 pipe longitudinal direction due to slippage at the pipe-soil interface; and (3) tensile stress due to the 
axial elongation of the HDPE pipes. However, in the existing methods the performance of pipes associated with localized ground subsidence is not well considered.

Buried pipes subjected to the ground subsidence are normally analyzed using the beams on Winkler elastic foundation model, in which the pipe is represented as a beam-type structural element surrounded by a series of independent nonlinear soil springs (ASCE 1984; ALA 2001; Shen et al. 2014). The value of soil spring stiffness depends on the pipe-soil relative displacement and properties of the soil medium, i.e., internal friction angle, cohesion, and unit weight (Yin et al., 2011, 2017; Yin and Chang, 2013). However, it is difficult to estimate pipe-soil relative displacement because the effect of a pipe on ground subsidence propagation has not been well explored. In addition, phenomenon of pipe-soil separation has been reported in some previous studies (e.g., Vorster 2005; Vorster et al. 2005; Wang et al. 2015). It is observed that the bending behavior of the pipe with ground subsidence is affected significantly by the pipe-soil separation. However, the pipe-soil separation cannot be simulated by the beams on Winkler elastic foundation model because the spring stiffness cannot be set to zero. Consequently additional stress and strain caused by localized ground subsidence will be overestimated. A curve-fitting technique for predicting pipe deformation with the ground subsidence is extensively employed (e.g., Newmark and Hall 1975; Kennedy et al. 1977; Wang and Yeh 1985; O'Rourke 1989; Karamitros et al. 2007; Trifonov and Cherniy 2012; Karamitros et al. 2011, Newmark and Hall, 1975). In the method, the effect of pipe bending stiffness on the pipe deformation is neglected and the buried pipe deforms as a catenary shape under the strike-slip fault. Wang and Yeh (1985) approximate the deformed pipe segment crossing the fault zone by a circular arc, and the deflection at far ends of buried pipes fitted by using trigonometric functions. O'Rourke (1989) employs the cosine function and fixed-fixed beam model to calculate the 
deformation of flexible and rigid pipes, respectively. However, the calculation procedures are too complicated in terms of many site-specific parameters for practical application.

The pipe-soil interaction under the ground movement condition has been investigated using different testing approaches, such as field tests, centrifuge model tests and large-scale model tests. Chan and Wong (2004) report a field case study on the steel pipe responses to landslides. They find that the transverse soil movement has more significant effect on the structural behaviors of the pipes than the longitudinal one. Li et al. (2012) investigate the influence of faulting offset and pipe dimensions on behaviors of buried HDPE pipe subjected to faulting through laboratory model tests. Their results show that the pipe with larger flexural stiffness has smaller bending strains. Centrifuge tests are another effective tool to investigate the pipe responses to the ground subsidence (e.g., O'Rourke et al. 2005; Vorster 2005; Bransby et al. 2007; Choo et al. 2007; Ha et al. 2008; White et al. 2008; Daiyan et al. 2011; Saiyar 2011 and Saiyar et al. 2016). O'Rourke et al. (2005) report that the pipe strains measured from the tests are compared with those from finite element (FE) modeling, and it is seen that the centrifuge technology is capable of reproducing the pipe responses subjected to the strike-slip fault. Vorster (2005) conducts a series of centrifuge modeling tests with $75 \mathrm{~g}$ acceleration to investigate the pipe responses to the tunneling-induced ground subsidence. Three types of model pipes, i.e., two aluminum alloy pipes and one acrylic pipe, with radius/thickness ratios of 21,12 , and 7 are used. Saiyar (2011) performs centrifuge tests with $30 \mathrm{~g}$ acceleration to investigate the pipe-soil interaction for pipes crossing normal faults. Solid rods with a length of $0.8 \mathrm{~m}$ and a diameter of 9.5 $\mathrm{mm}$ are fabricated to generate equivalent bending stiffness with the prototype pipes. Because the wall thickness of the profiled wall pipes is only several millimeters (e.g., double-wall corrugated HDPE pipes with liner thickness of less than $5 \mathrm{~mm}$ ), it is very difficult to produce centrifuge modelling 
Large-scale model tests are widely used for a reliable database characterizing ground

121 subsidence-induced pipe responses (e.g., Trautmann and O'Rourke 1983; Yoshizaki et al. 2003;

122 Anderson et al. 2005; Weerasekara and Wijewickreme 2008; O'Rourke et al. 2010; Almahakeri et al.

123 2012; Yang et al. 2012; Wang et al. 2015). Trautmann and O'Rourke (1983) conduct laboratory

124 model tests to investigate the response of steel pipes with diameters of 102 and $324 \mathrm{~mm}$ subjected to

125 ground movements associated with earthquakes. They find that the relationship between earth

126 pressure and displacement of the pipe can be represented by bilinear or hyperbolic functions.

127 Almahakeri et al. (2012) investigate the responses of 115-mm-diameter and 1830-mm-long glass

128 fiber reinforced polymers pipes buried in dense sand subjected to the ground movement. They report

129 that the peak earth pressure acting on the pipe increases with the burial depth. It is recognized that

130 the earth pressure acting on the pipe is essential for estimating additional stress and deformation of

131 the pipe with ground subsidence (Jiang and Yin, 2012, 2014). However, very limited studies are

132 found in the literature about the earth pressure acting on the flexible pipes subjected to the ground

133 subsidence.

In addition, pipelines are buried in the ground and thus the displacement and internal forces are

difficult to measure in practice. Therefore, an alternative way by using the ground surface settlement trough to predict the additional displacement and internal force of pipes is valuable (e.g., Duan 2002; Wang et al. 2015; Ni 2016). Duan (2002) proposes a method to predict the deformation of pipes subjected to tunneling based on the volume loss of ground surface. Wang et al. (2015) investigate the ground responses to tunneling considering the existence of HDPE double-wall corrugated pipes. The moveable bottom plates of the model box are lowered to form normal distribution curves for 
141 simulating the ground movement induced by tunneling. They find that the existence of HDPE pipes 142 induces a wider but shallower soil settlement trough as compared to the free field (i.e., no pipe). Ni 143 (2016) establishes a design framework to calculate the bending strain of buried pipes subjected to the 144 normal fault based on the estimation of trough width parameter at the ground surface (i.e., the 145 distance from the point of inflection to the peak curvature point). Nevertheless, the response of 146 HDPE pipe to localized ground subsidence (i.e., an area with deep and narrow depression) has not 147 been well understood. The localized ground subsidence can be caused by soil pumping, karst 148 evolution, ground collapse due to pipe leak, and so on.

149 In this study, a series of large-scale model tests are conducted to investigate the structural 150 responses of HDPE double-wall corrugated pipes subjected to localized ground subsidence. The 151 movable plates installed at the bottom of the model box are lowered down in designed sequences to 152 simulate the progressive development of the ground subsidence. Earth pressures, vertical 153 displacements of the pipe, and settlements at different depth are monitored during the tests. The 154 effects of bending stiffness and burial depth of the pipe on its structural responses are investigated. A 155 correlation of pipe displacement and the settlement trough at the ground surface is developed. The result of this study is useful for understanding both qualitatively and quantitatively the performance 157 of buried flexible pipes subjected to localized ground subsidence.

1592 Testing Instrumentation and Measurements

\subsection{Testing pipes and backfilling materials}

Four HDPE double-wall corrugated pipes (labeled as P1, P2, P3 and P4) with inner diameters of 
163 pipes are tabulated in Table 1. Yangtze River sand is used as the backfill material. The sand is first 164 air dried and passed through a sieve with an opening size of $2 \mathrm{~mm}$ to exclude large particles. The 165 specific gravity, measured in accordance with ASTM D854 (ASTM 2014), is 2.65, and the minimum 166 and maximum densities, measured in accordance with ASTM D4253 (ASTM 2014), are 1.39 and $1671.51 \mathrm{Mg} / \mathrm{m}^{3}$, respectively. The gradation characteristics of the sand are listed in Table 2. Based on 168 the Unified Soil Classification System, ASTM D2487 (ASTM 2011), the sand is classified as poorly 169 graded sand (SP).

Table 1 Physical properties of the HDPE pipes

172

173 174

\begin{tabular}{cccccc}
\hline $\begin{array}{c}\text { Pipe } \\
\text { ID }\end{array}$ & $\begin{array}{c}\text { Inner pipe } \\
\text { diameter } \\
(\mathrm{mm})\end{array}$ & $\begin{array}{c}\text { Inner wall } \\
\text { thickness } \\
(\mathrm{mm})\end{array}$ & $\begin{array}{c}\text { Laminated } \\
\text { wall } \\
\text { thickness } \\
(\mathrm{mm})\end{array}$ & $\begin{array}{c}\text { Depth of } \\
\text { corrugation } \\
(\mathrm{mm})\end{array}$ & $\begin{array}{c}\text { Pitch of } \\
(\mathrm{mm})\end{array}$ \\
\hline P1 & 200 & 1.2 & 1.7 & 10 & 30 \\
P2 & 300 & 1.7 & 2.2 & 15 & 40 \\
P3 & 300 & 1.7 & 2.2 & 15 & 40 \\
P4 & 400 & 2 & 2.5 & 25 & 50 \\
\hline
\end{tabular}

Table 2 Gradation characteristics of Yangtze River sand

\begin{tabular}{lc}
\hline \multicolumn{1}{c}{ Parameters } & Value \\
\hline Particle size fraction & \\
Medium sand $(0.425-2 \mathrm{~mm})(\%)$ & 27.44 \\
Fine sand $(75-425 \mu \mathrm{m})(\%)$ & 72.56 \\
$D_{60}(\mathrm{~mm})$ & 0.40 \\
$D_{30}(\mathrm{~mm})$ & 0.23 \\
$D_{10}(\mathrm{~mm})$ & 0.14 \\
Uniformity coefficient $C_{\mathrm{u}}$ & 2.86 \\
Curvature coefficient $C_{\mathrm{c}}$ & 0.94 \\
\hline
\end{tabular}

175

176

\subsection{Test apparatus}

The physical model box is $2.0 \mathrm{~m}$ in width, $2.0 \mathrm{~m}$ in length and $1.5 \mathrm{~m}$ in height, as shown in Fig. 
1. The side walls of the box except for the front one are made of 15 -mm-thick polyethylene sheets and stiffened by steel frames to minimize side deflections. The front wall is made of Plexiglas plate with a thickness of $12 \mathrm{~mm}$, allowing visual observation of soil movements. The bottom of the box is made up of eight movable plates, and each plate is $0.10 \mathrm{~m}$ thick, $0.25 \mathrm{~m}$ wide and $2 \mathrm{~m}$ long. Lowering devices are used to control the vertical movement of the bottom plates by manually rotational handles beneath the model box, and each individual lowering device connects to a single movable bottom plate. The maximum lowering distance of the bottom plates is $100 \mathrm{~mm}$, and ten rounds of handle results in $1 \mathrm{~mm}$ displacement. Details of the instrumentations can be found in Wang et al. (2015). Two fixing frames are designed to connect the ends of HDPE pipes with the wall of the model box where no occurance of pipe-soil slippage-occurs. A pipe plug mounted on the fixing frame could be pushed into the pipe end to simulate a spigot joint, and a 1.5-mm-thick rubber gasket is also $\underline{\text { installed between the plug and test pipe to tighten the connection. }}$

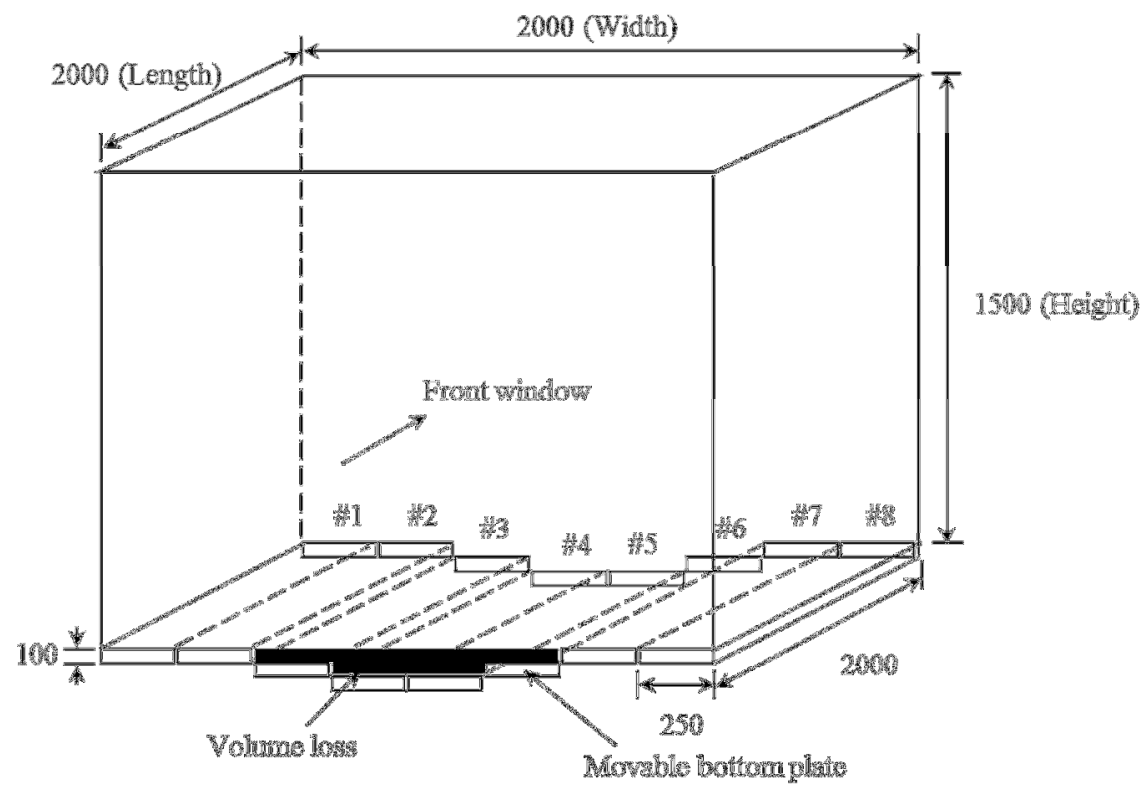


custom-made sand pluviation device. The sand is first lifted up to the pluviation device by a belt conveyor, and then falls into the model box from a sieve with an opening size of $2 \mathrm{~mm}$ installed at the bottom of the pluviation device to exclude large particles and to eliminate the velocity effect of sand particles on the backfill density. In order to keep the falling height of the sand consistent, the pluviation device is moved upward by $0.1 \mathrm{~m}$ after a $0.1-\mathrm{m}$-thick sand layer is backfilled into the box. Prior to filling, the relationship between the falling height and density of the sand is obtained by conducting a pluviation test, as shown in Fig. 2 (Wang et al. 2015). The falling height of the sand adopted in the tests is $0.7 \mathrm{~m}$, and the corresponding sand density is $1.46 \mathrm{Mg} / \mathrm{m}^{3}$. The state of compactness of the sand is defined as medium dense with a relative density of $62 \%$ and constrained modulus is estimated as $3.52 \mathrm{MPa}$ under overburden stress of $12.5 \mathrm{kPa}$ (similar with the overburden stress at the level of pipe axis, i.e., $13.1 \mathrm{kPa}$ for the $\mathrm{P} 1, \mathrm{P} 2$ and $\mathrm{P} 4$ pipes and $8.8 \mathrm{kPa}$ for the $\mathrm{P} 3$ pipe) using the method suggested by ASTM D2435M (ASTM 2011). The internal friction angle of the sand with density of $1.46 \mathrm{Mg} / \mathrm{m}^{3}$ is determined as $32.5^{\circ}$ by direct shear tests as per ASTM D3080 (ASTM 2011).

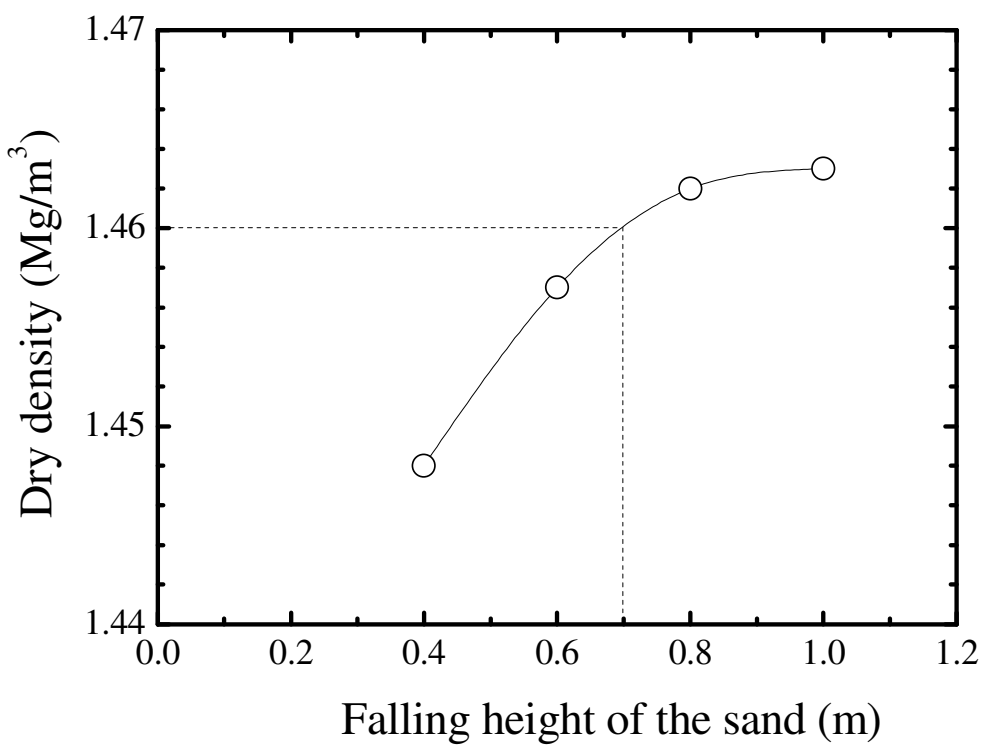



the pipe and the settlement at different depth. Schematic diagram of the settlement plate is shown in 215 Fig. 3 (Wang et al. 2015). Two square plates with side length of $50 \mathrm{~mm}$ and thickness of $5 \mathrm{~mm}$ are 216 fixed on the ends of 10-mm-diameter rods, and the rods are enclosed in PVC tube to eliminate the 217 friction between settlement plate and sand. In order to reduce the effects of self-weight of the settlement plates on the settlement measurement, the square plates and rods are made of lightweight plexiglass. The dial gauge used in this study has a range of 0 to $50 \mathrm{~mm}$ and an accuracy of $0.1 \mathrm{~mm}$. and resolution are $0.5 \%$ Full Scale (FS) and $0.01 \%$ FS, respectively. A data acquisition system is connected with the earth pressure cells to record data at a time interval of two seconds automatically. the manufacturers to ensure the accuracy of the test results. 


\subsection{Test methods}

$\mathrm{P} 1, \mathrm{P} 2$ and $\mathrm{P} 4$ pipes have a burial depth of $0.9 \mathrm{~m}$ (i.e., the distance from the axis of the pipe to

233 the backfill surface), while the burial depth of P3 pipe is $0.6 \mathrm{~m}$. Settlement propagation is also

234 observed in the free field (i.e., no pipe) condition. The details of all test cases are shown in Table 3.

235 Three measuring sections are setup to capture the earth pressure and settlement distribution of the

236 soil and pipe. Section 1 is located at a horizontal distance of $500 \mathrm{~mm}$ from the centerline of the pipe,

237 Section 2 is located at the center of the pipe, and Section 3 is $250 \mathrm{~mm}$ from the centerline, as shown

238 in Fig. 4. Earth pressure cells are installed at the pipe top at Sections 1 and 2. For the P4 pipe, the 239 earth pressure cells are also installed at the bottom of the pipe at Sections 1 and 2 to record the 240 potential pipe-soil separation with the development of the subsidence simulated by lowering of 241 bottom moveable plates. Settlement plates are placed at the pipe top at Sections 1, 2 and 3 to measure 242 the vertical displacement of the pipe. The settlement at the backfill surface is measured by placing 243 the foot of dial gauge on a lightweight plexiglass square plate with a side of $50 \mathrm{~mm}$ placed on the 244 backfill surface. In the free field case, the settlement plates are placed at the depths of 0, 0.3, 0.6 and 2450.9 m, respectively, as shown in Fig. 4(e).

Table 3 Summary of test cases

\begin{tabular}{cccccccc}
\hline Cases & Pipe ID & $A\left(\mathrm{~m}^{2} / \mathrm{m}\right)$ & $E A(\mathrm{kN} / \mathrm{m})$ & $E I\left(\mathrm{kNm}^{2}\right)$ & $\begin{array}{c}\text { Pipe } \\
\text { stiffness } \\
(\mathrm{kPa})\end{array}$ & $\begin{array}{c}\text { Inside pipe } \\
\text { diameter } \\
(\mathrm{mm})\end{array}$ & $\begin{array}{c}\text { Burial depth } \\
(\mathrm{m})\end{array}$ \\
\hline 1 & $\mathrm{P} 1$ & 0.0044 & 2000 & 5 & 215 & 200 & 0.9 \\
2 & $\mathrm{P} 2$ & 0.0067 & 3000 & 18 & 215 & 300 & 0.9 \\
3 & $\mathrm{P} 3$ & 0.0067 & 3000 & 18 & 215 & 300 & 0.6 \\
4 & $\mathrm{P} 4$ & 0.0078 & 3500 & 48 & 215 & 400 & 0.9
\end{tabular}




\section{$5 \quad$ No pipe}

$248{ }^{\mathrm{a}}$ From the horizontal centerline of the pipe to the backfill surface

249 Note: $E$ = pipe material modulus of elasticity; $A=$ sectional area of the pipe wall per unit length; $I=$ moment of 250 inertia of the pipe.

251
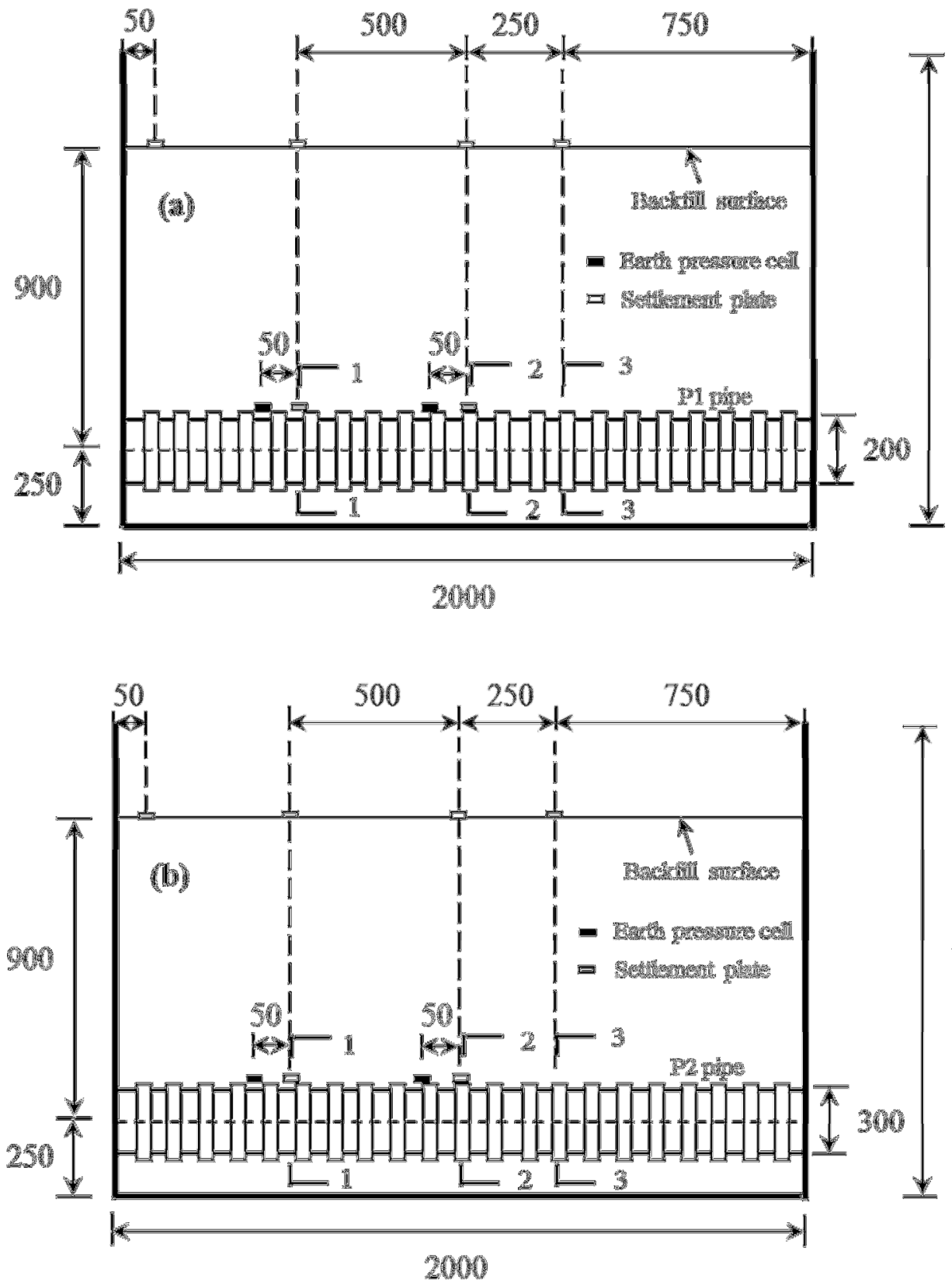


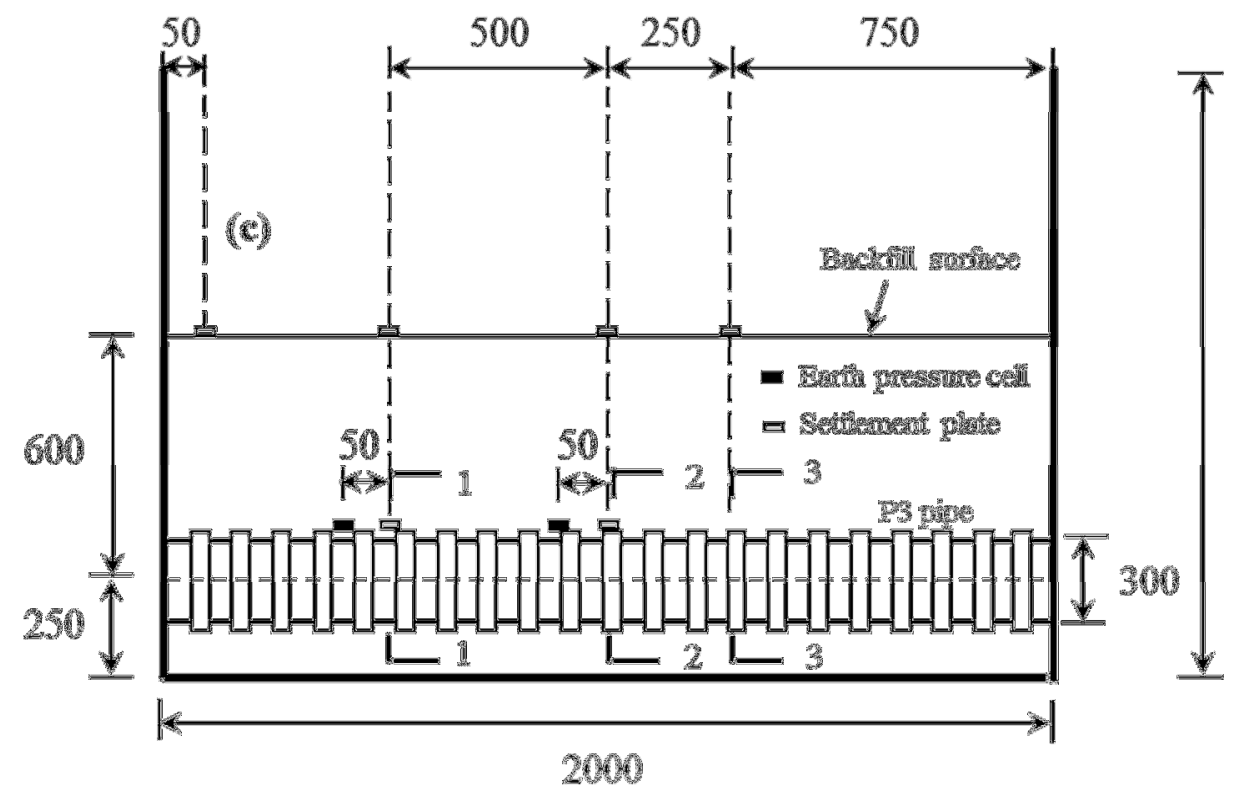

1500

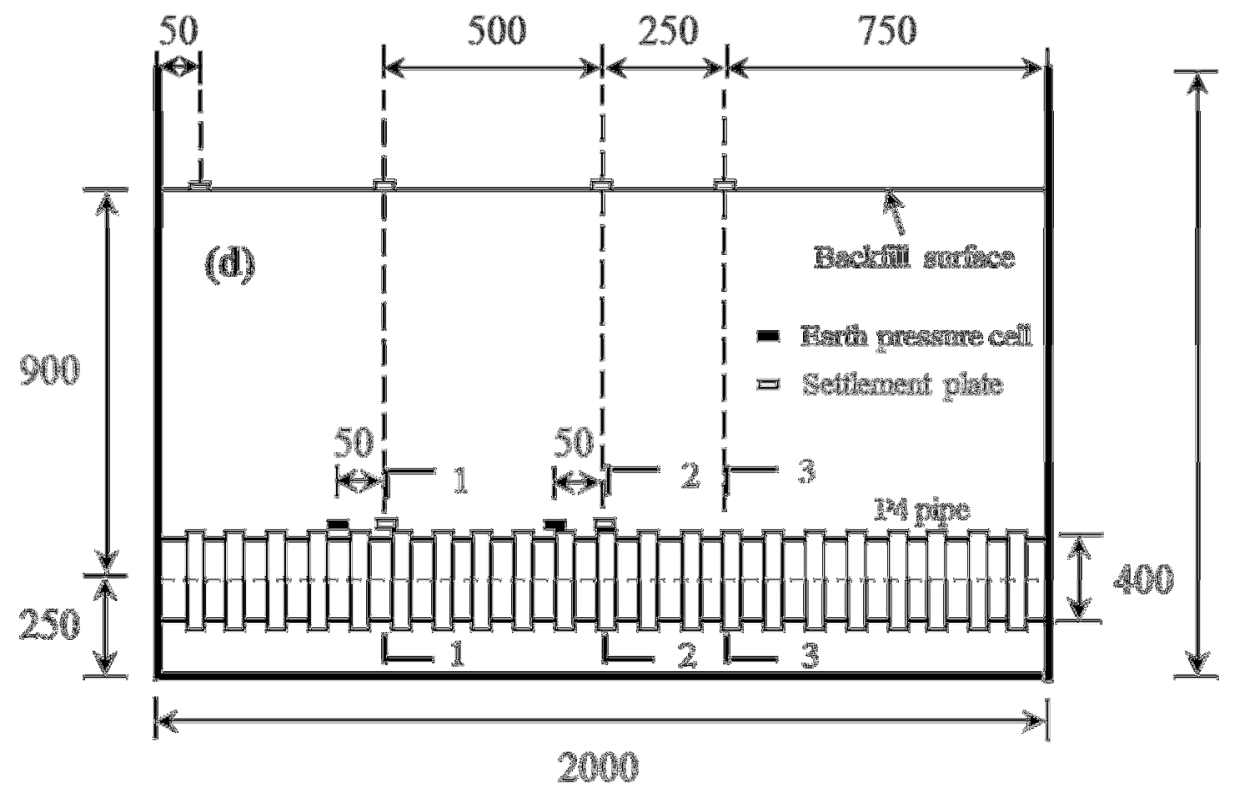

1500 


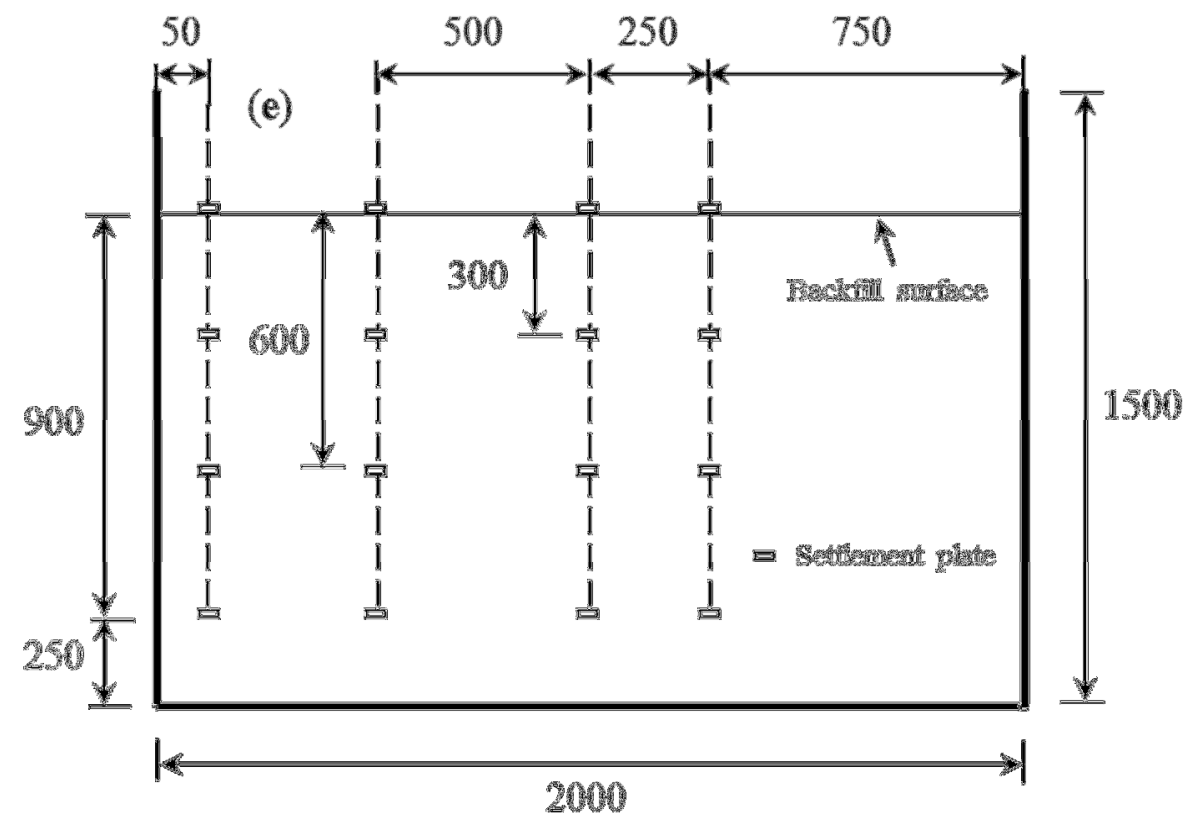

The range and magnitude of localized ground subsidence are simulated by lowering down the bottom plates in a designed sequence (labeled as \#3, \#4, \#5 and \#6 in Fig. 1). Moving patterns of the bottom plates of the model box (i.e., $\mathrm{A} \rightarrow \mathrm{B} \rightarrow \mathrm{C} \rightarrow \mathrm{D} \rightarrow \mathrm{E} \rightarrow \mathrm{F}$ ) are shown in Fig. 5. The bottom plates \#4 and \#5 are lowered at the same time with sequences of first, third and fifth (represented as A, C and E), and then bottom plates \#3 and \#6 are lowered with the sequences of second, fourth and sixth (represented as B, D and F). The stoppage time after each lowering of the bottom plates is left to stabilize the pipe responses (i.e., the increasing of vertical displacement of the pipe is less than $1 \mathrm{~mm}$ in 24 hours). The rotation rate of the handle is controlled as 30 rounds/min to lower down the bottom plates with a rate of $3 \mathrm{~mm} / \mathrm{min}$. Vaseline is placed on the wall of the model box to minimize the effect of the friction between the side wall and the backfill. 

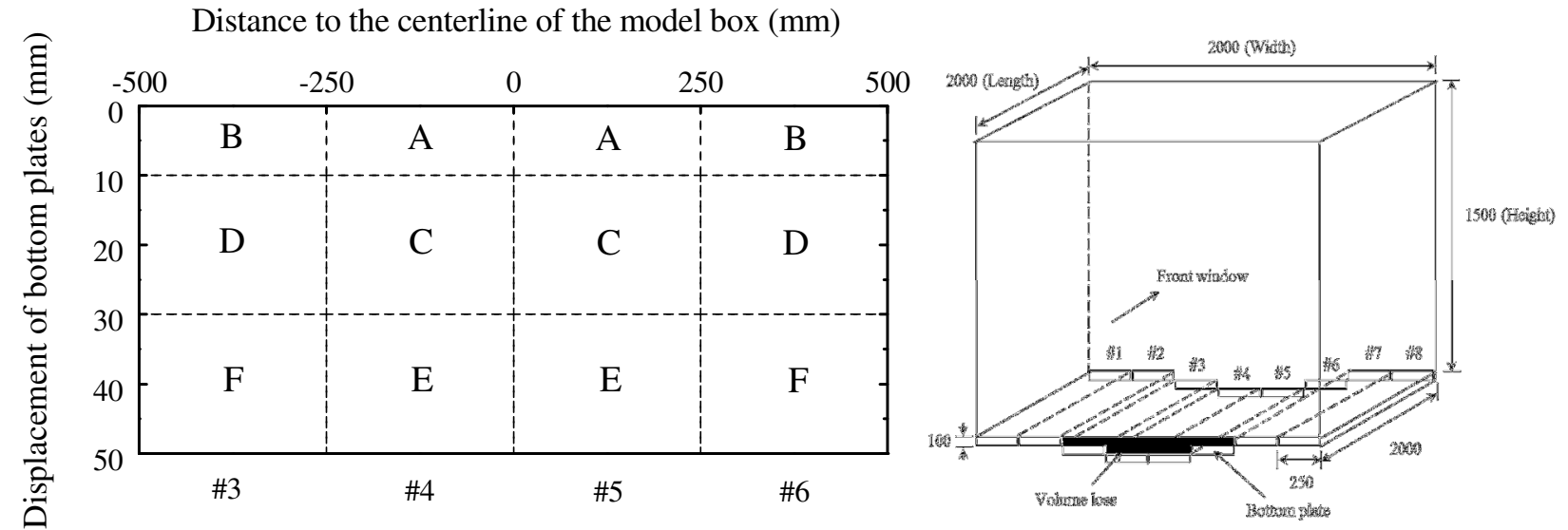

Fig. 5 Moving patterns of the bottom plates (letters A throughout F represent the lowering sequence)

\section{Results and Analyses}

\subsection{Free field soil settlement}

Gaussian curves have been widely adopted to predict surface settlement caused by tunneling

(e.g., Peck 1969; Attewell and Farmer 1974; Attewell et al. 1986; Wang et al. 2015):

where $S_{\max }$ is the maximum soil settlement $(\mathrm{m}) ; i$ is the trough width parameter corresponding to the distance from the centerline of the subsidence trough to the point of inflection $(\mathrm{m})$; and $x$ is the distance to the centerline of the ground subsidence zone (m).

Figure 6 shows the variation of the free field settlement at different depth $(Z)$ with lowering sequence of the bottom plates. It is found that Eq. (1) does not provide a good prediction of the measured settlement in this study. The fitting by using Eq. (1) yields a value of coefficient of determination, $R^{2}$, less than 0.7. Gaussian curves by Eq. (1) is not general enough (Celestino et al. 2000). In this study, a modified five-parameter Gaussian function is developed and expressed by:

$$
S_{v}=m S_{\max }\left(\exp \left(-0.5(n x / i+\alpha)^{2}\right)+\exp \left(-0.5(n x / i-\alpha)^{2}\right)\right)
$$

$$
m=0.5 \exp \left(0.5 \alpha^{2}\right)
$$




$$
\exp (-2 n \alpha)\left(1-(n+\alpha)^{2}\right)=(n-\alpha)^{2}-1
$$

290 where $\alpha$ is a parameter influencing the shape of the curve as shown in Fig. 7, and $m$ and $n$ are 291 parameters to ensure that $S_{\max }$ and $i$ remain the maximum soil settlement and the distance to the 292 inflection point, respectively. In this study, $\alpha=0.5$ is assumed.

293 It is seen in Fig. 7 that the curvature of modified Gaussian function with $\alpha=1.0$ at $x / i=0$ is 294 smaller than that for the curve with $\alpha=0.5$. In other words, as $\alpha$ increases, the modified Gaussian 295 function becomes flat gradually nearby the maximum soil settlement. Eq. (2) reverts to Gaussian 296 function (Eq. (1)) for $\alpha=0$.

Distance to the centerline of model box $(\mathrm{m})$

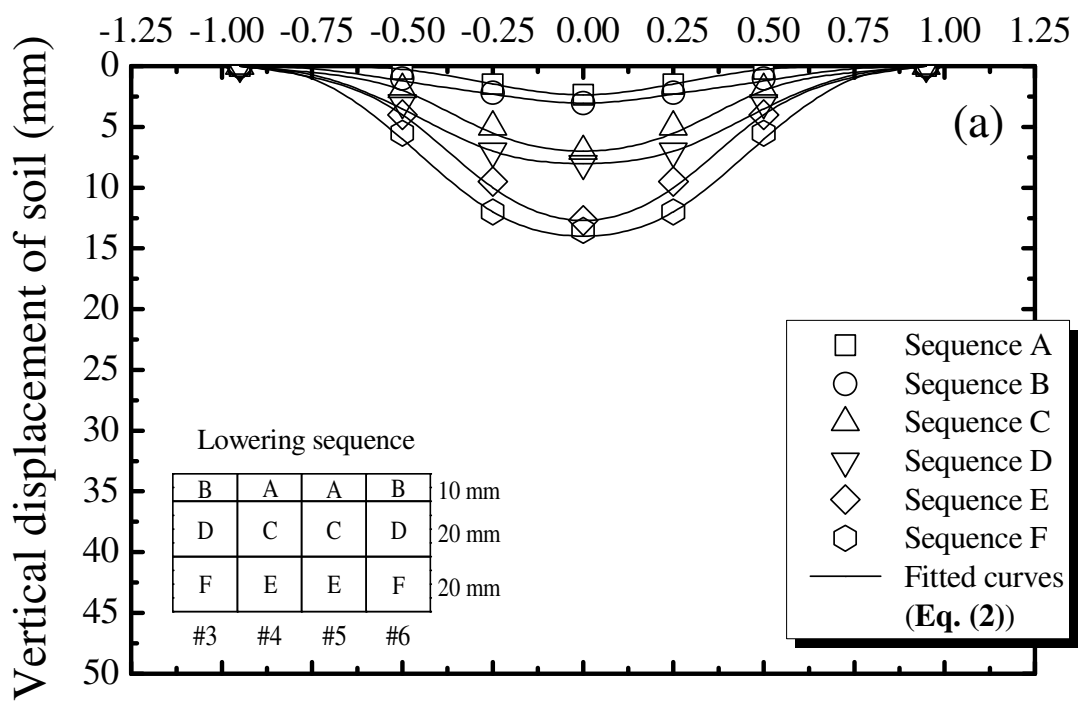


Distance to the centerline of model box (m)

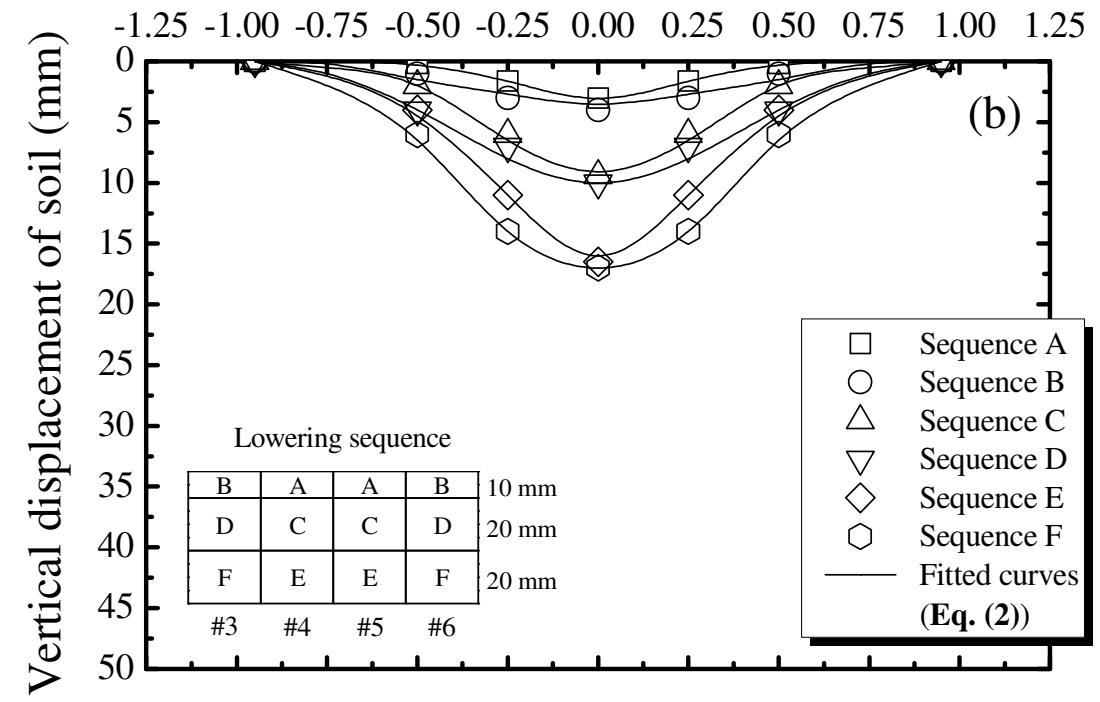

Distance to the centerline of model box (m)

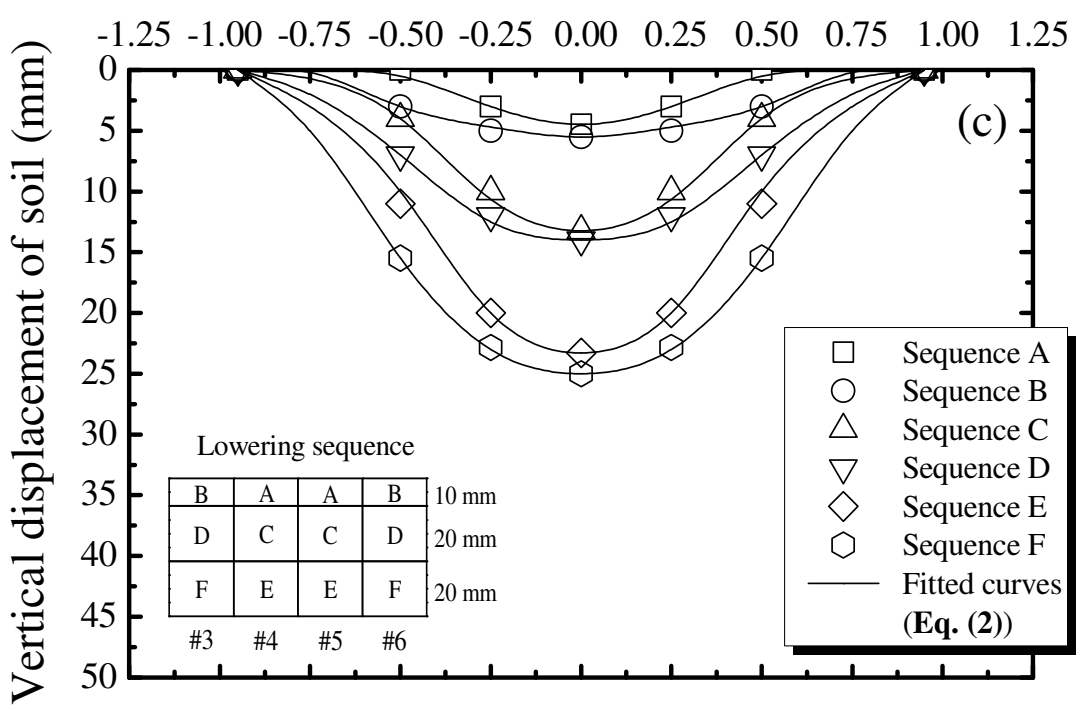

Distance to the centerline of model box (m)

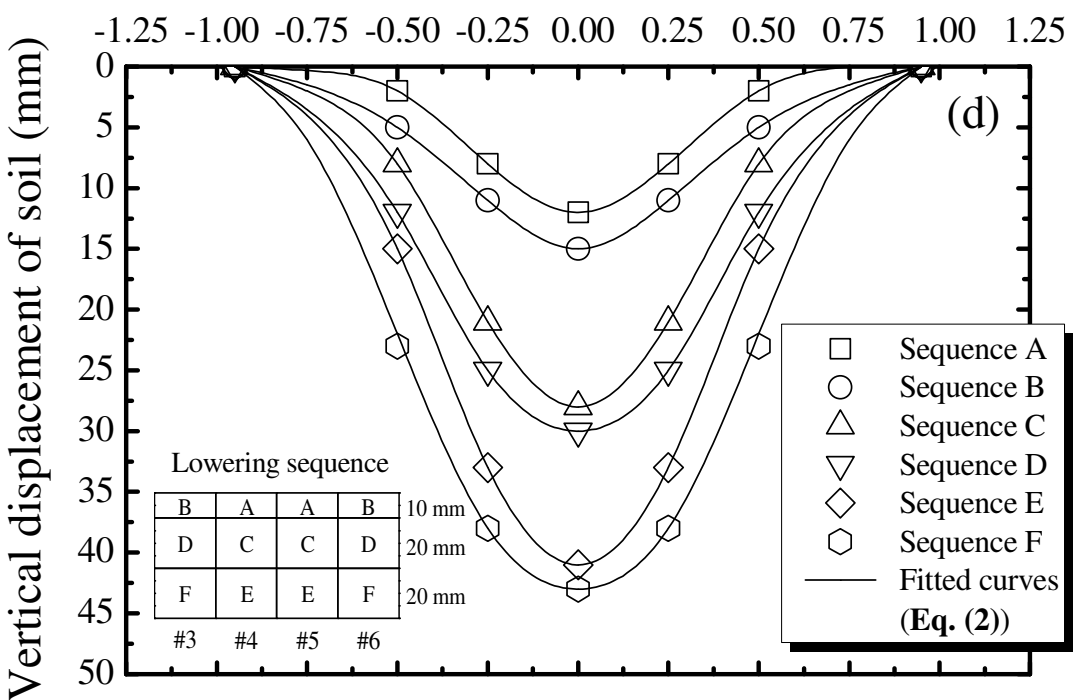


Fig. 6 Free field soil settlement: (a) $Z=0 \mathrm{~m}$; (b) $Z=0.3 \mathrm{~m}$; (c) $Z=0.6 \mathrm{~m}$; and (d) $Z=0.9 \mathrm{~m}$ ( $Z$ represents the initial depth of the settlement plate when the backfilling is completed)

$$
x / i
$$

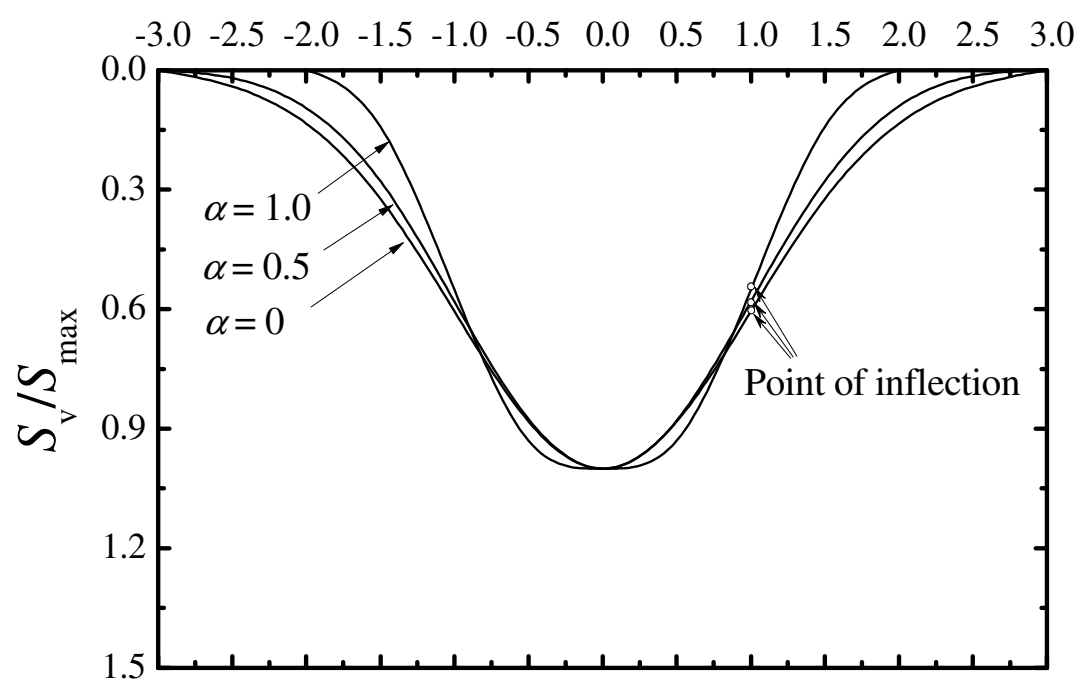

Fig. 7 Influence of $\alpha$ on the modified Gaussian function

Figure 8 shows the variation of the trough width parameter at different depths (denoted as $\left.i_{\text {soil }}\right)$ with lowering sequence of the bottom plates in the free field condition. It is seen that the value of $i_{\text {soil }}$ decreases with depth. It illustrates that the settlement tends to spread to a wider range when it propagates upwards to the backfill surface. It is also found that $i_{\text {soil }}$ increases when plates \#3 and \#6 are lowered down at the second, fourth and sixth sequences (represented as B, D and F), while $i_{\text {soil }}$ decreases when plates \#4 and \#5 are lowered down with the sequences of third and fifth (represented as $\mathrm{C}$ and $\mathrm{E}$ ), as compared with the value of $i_{\text {soil }}$ with lowering plates \#3 and \#6 at Sequences B and D. 


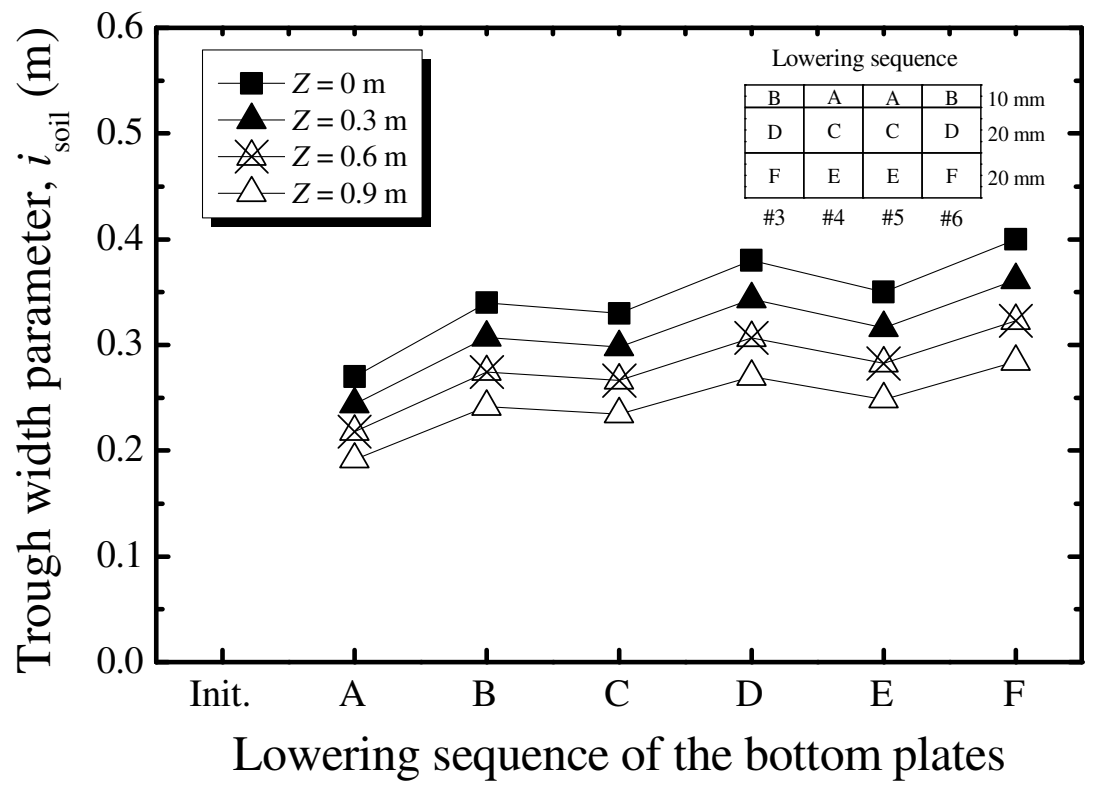

Fig. 8 Variation of the trough width parameter $\left(i_{\text {soil }}\right)$ with the lowering sequence of the bottom plates in free field case ("Init." represents the completion of the backfilling)

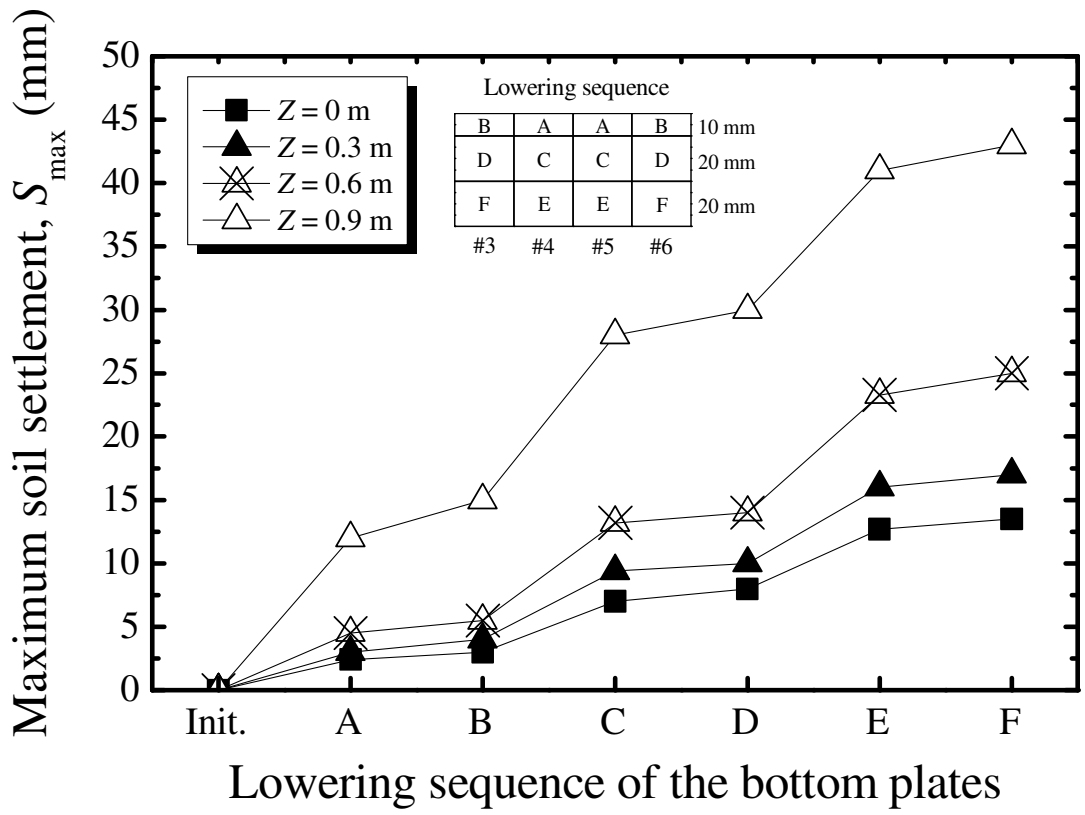

Fig. 9 Variation of the maximum soil settlement $\left(S_{\max }\right)$ with the lowering sequence of the bottom plates in free field case

Figure 9 shows the variation of the maximum soil settlement $\left(S_{\max }\right)$ at different depths with lowering sequence of the bottom plates. It is seen that the value of $S_{\max }$ increases with depth. Figures 8 and 9 show the settlement troughs become narrower (i.e., $i_{\text {soil }}$ decreases) and the maximum settlement becomes larger when burial depth increases. The value of $S_{\max }$ increases sharply with the 

and E), while it increases slightly with lowering of the bottom plates \#3 and \#6 with the sequences of second, fourth and sixth (represented by B, D and F).

Figure 10 presents the variation of the volume of the settlement trough $\left(V_{\text {soil }}\right.$, unit: $\left.\mathrm{m}^{3} / \mathrm{m}\right)$ at ( $\left.V_{\text {soil }}\right)$ is calculated through the integration of Eq. (2) and expressed by the following equation:

$$
V_{\text {soil }}=2 \sqrt{2 \pi} m S_{\text {max }} i_{\text {soil }} / n
$$

It is seen that $V_{\text {soil }}$ increases with depth, which is consistent with the change of $S_{\max }$ shown in Fig. 9,

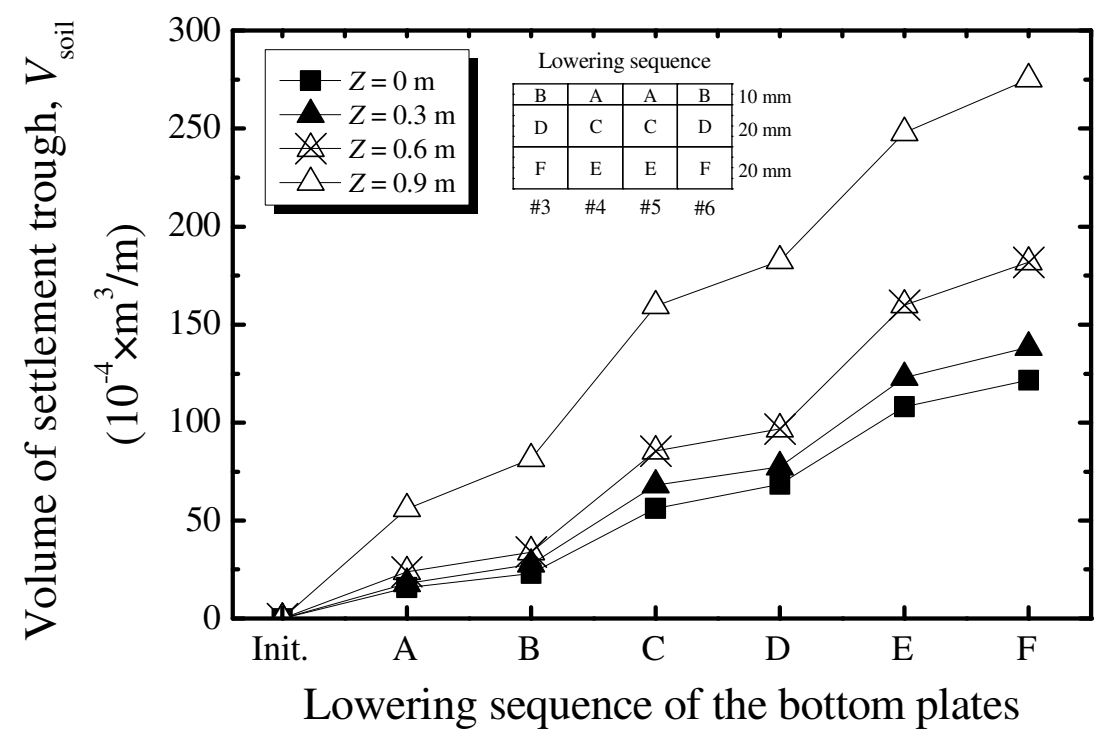

Fig. 10 Variation of the volume of the settlement trough in free field case

\subsection{Vertical displacement of the pipes}

Figure 11 shows the variation of vertical displacement of the P1, P2, P3 and P4 pipes with

342 lowering sequence of the bottom plates. Eq. (2) is employed to simulate the measured vertical displacements. Fig. 12 shows the variations of the maximum vertical displacement of the pipe $\left(S_{\text {pmax }}\right)$ 
344 and the maximum free field settlement at the level of pipe axis with lowering sequence of the bottom

345 plates. The values for $S_{\text {pmax }}$ change in the way as: $S_{\mathrm{pmax}}$ for $\mathrm{P} 4<S_{\mathrm{pmax}}$ for $\mathrm{P} 2<S_{\mathrm{pmax}}$ for P1. This is 346 consistent with the values of $E I$ of the pipes, i.e., $48 \mathrm{kNm}^{2}$ for $\mathrm{P} 4$ pipe, $18 \mathrm{kNm}^{2}$ for $\mathrm{P} 2$ pipe, and 5 $347 \mathrm{kNm}^{2}$ for $\mathrm{P} 1$ pipe.

348 Fig. 13 shows that the variation of $S_{\text {pmax }}$ normalized by the maximum free filed settlement at the 349 level of pipe axis with the $E I$ of the pipe. It is seen that the normalized $S_{\text {pmax }}$ decreases with $E I$ of the 350 pipe $\left(E I_{\mathrm{P} 1}<E I_{\mathrm{P} 2}<E I_{\mathrm{P} 4}\right)$. It is also found from Fig. 12 that the $S_{\mathrm{pmax}}$ values of the $\mathrm{P} 2$ pipe $(0.6 \mathrm{~m}$ 351 burial depth) are larger than those of the P3 pipe due to the relatively higher burial depth of P3 pipe $352(0.9 \mathrm{~m})$. The maximum free field settlement at the level of pipe axis is found to be largest, indicating 353 that the presence of pipes has limited the settlement of the backfill at the pipe top level.

Distance to the centerline of model box $(\mathrm{m})$

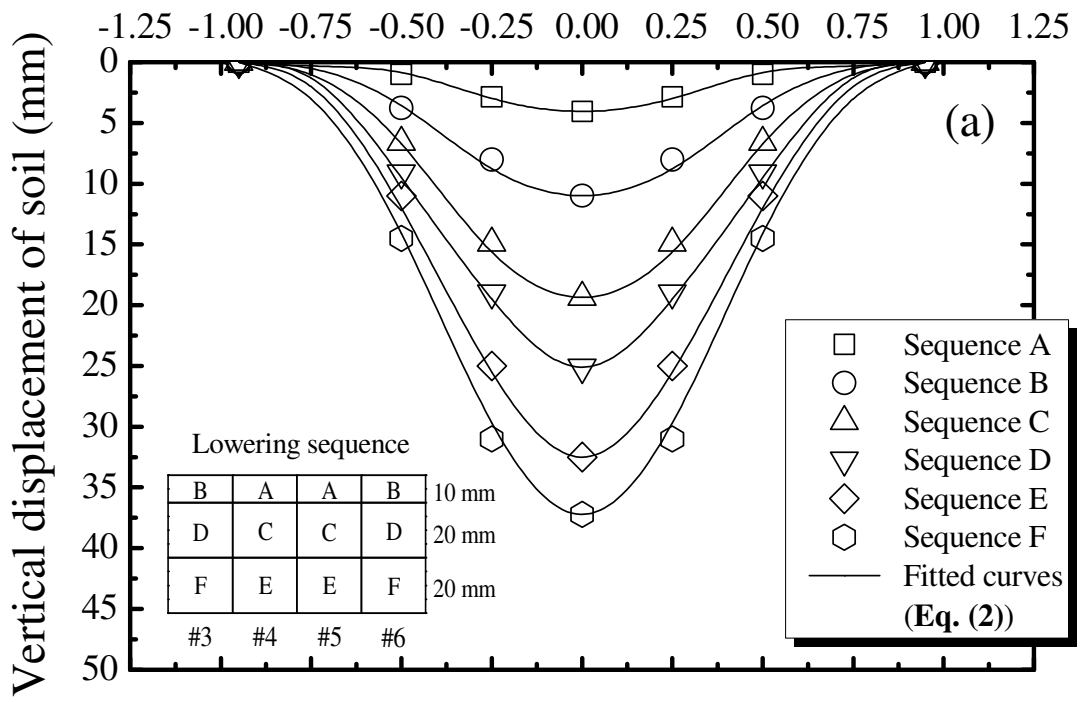


Distance to the centerline of model box (m)

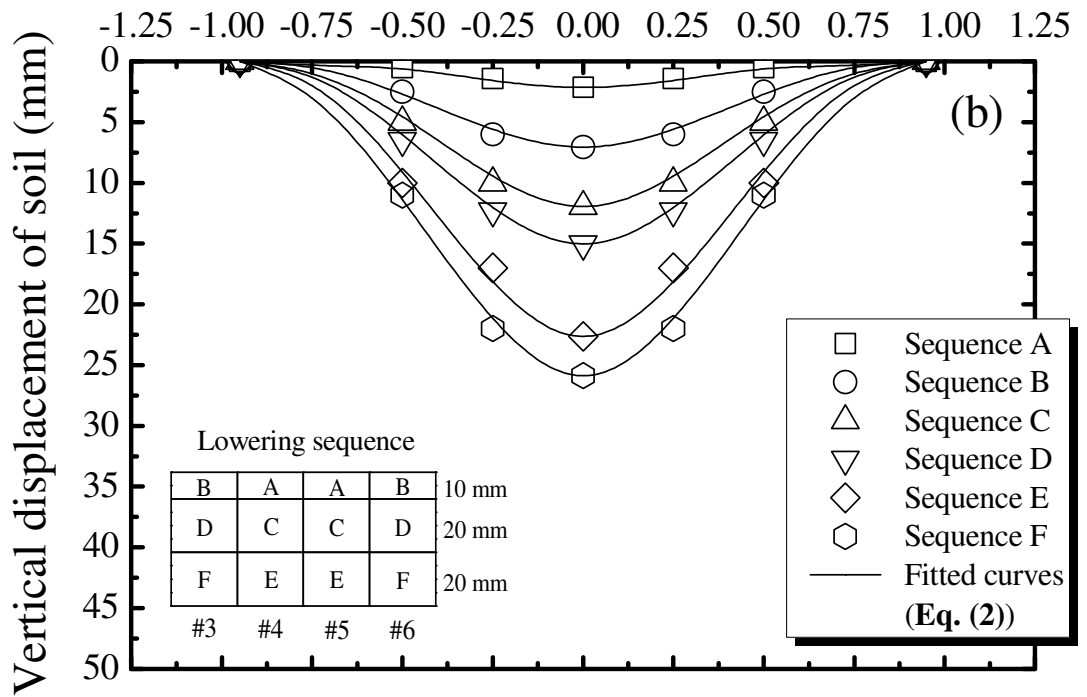

Distance to the centerline of model box (m)

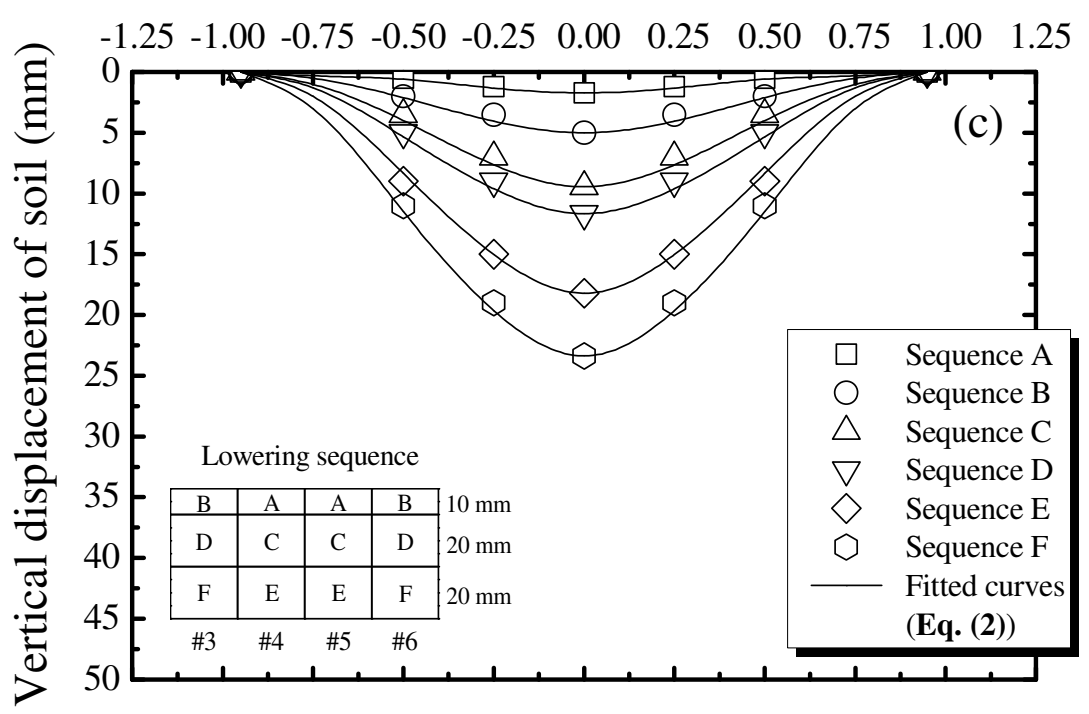

Distance to the centerline of model box (m)

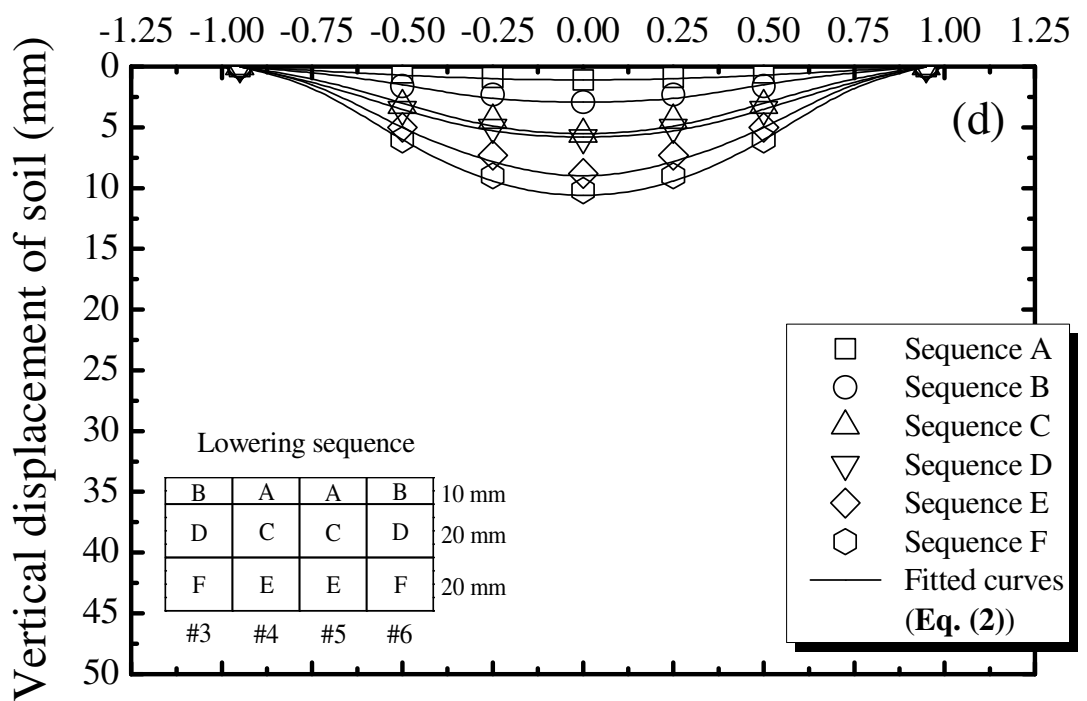


Fig. 11 Variation of the vertical displacement of the pipe with the lowering sequence of the bottom plates: (a) P1 pipe, (b) P2 pipe, (c) P3 pipe and (d) P4 pipe

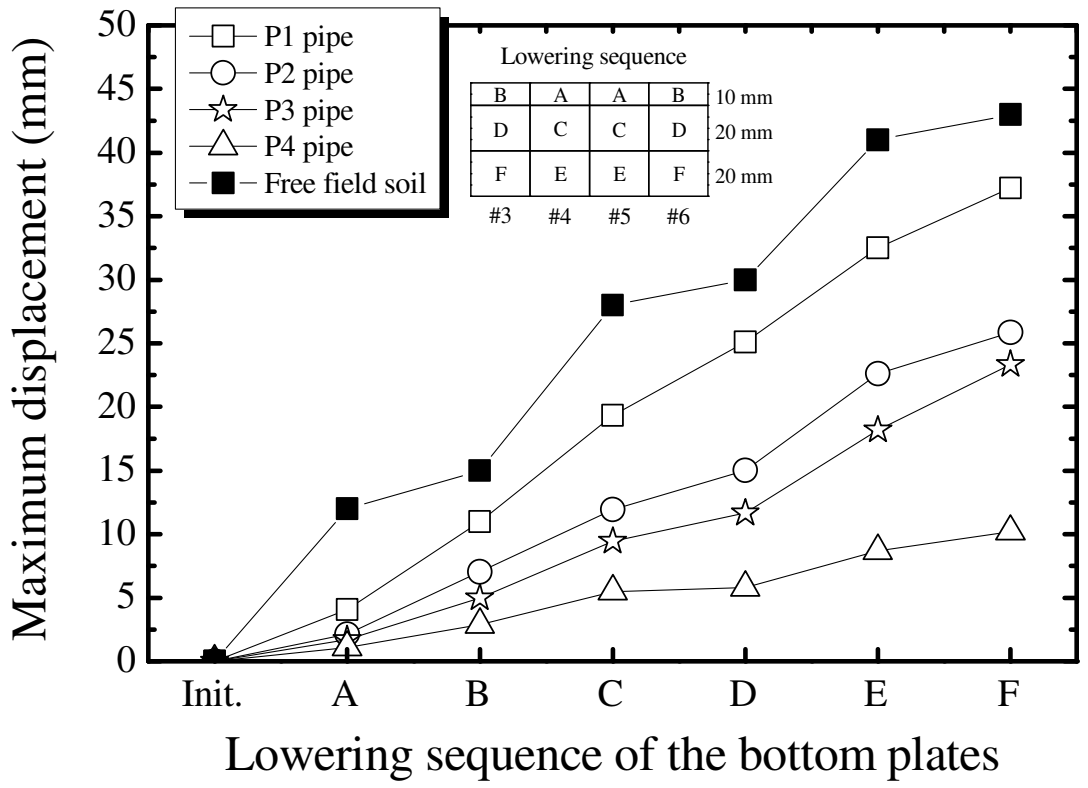

Fig. 12 Variation of the maximum displacement of pipe with the lowering sequence of the bottom plates

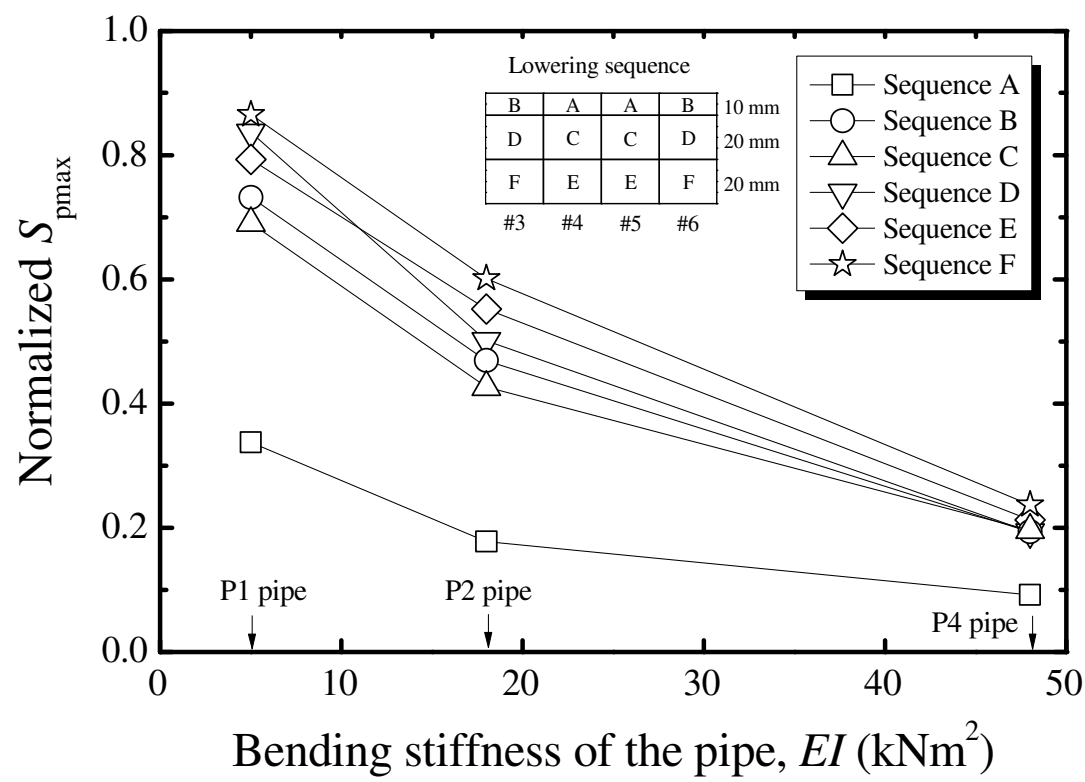

Fig. 13 Variation of normalized $S_{\text {pmax }}$ with bending stiffness of the pipe

Figure 14 shows the variation of the trough width parameter of pipe displacement profile $\left(i_{\mathrm{p}}\right)$ and that of free field settlement trough at the level of pipe axis with lowering sequence of the bottom plates. It is seen that the values of $i_{\mathrm{p}}$ change in the way as: $i_{\mathrm{p}}$ for $\mathrm{P} 4>i_{\mathrm{p}}$ for $\mathrm{P} 2>i_{\mathrm{p}}$ for $\mathrm{P} 1$, which is 

indicating that $i_{\mathrm{p}}$ decreases with burial depth. The trough width parameter of free field settlement trough at the level of pipe axis is found to be the smallest, indicating that the presence of the pipe spreads the soil settlement to a greater width. Stiffer pipe induces wider settlement trough.

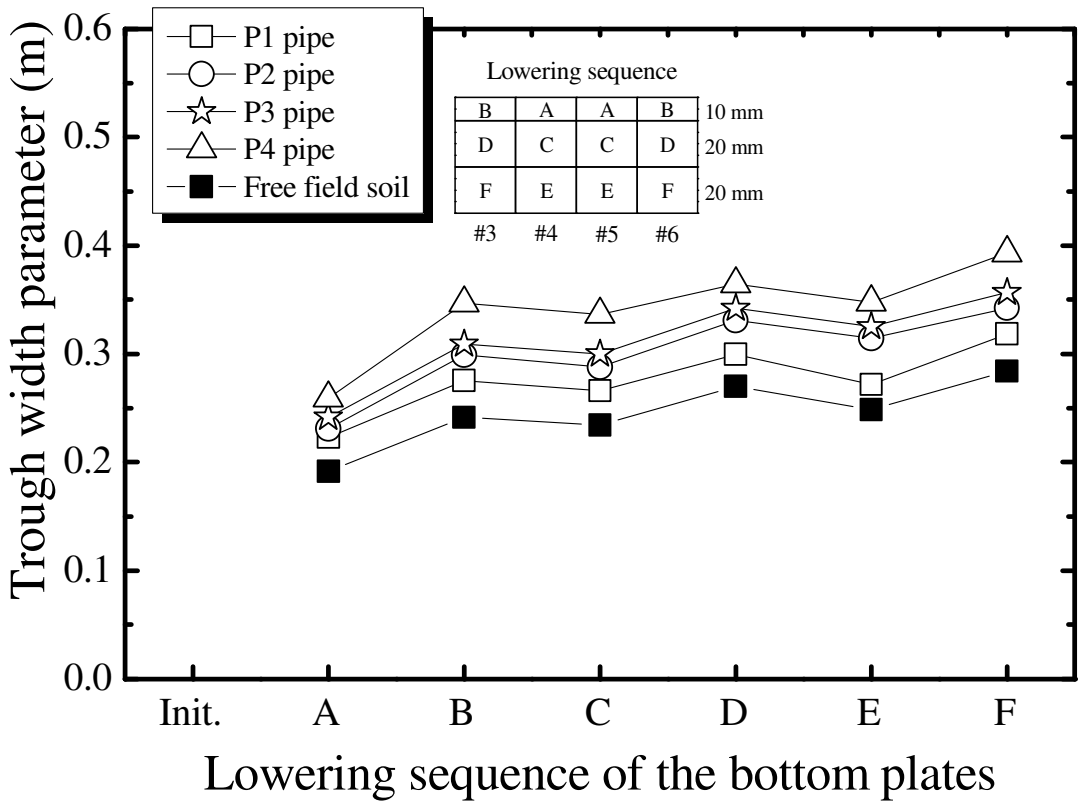

Figure 15 presents the variation of the volume of the pipe displacement profile $\left(V_{\mathrm{p}}\right)$ and that of free field settlement trough at the level of pipe axis. It is seen that the values of $V_{\mathrm{p}}$ values for the P1 pipe are larger than those of the P2 pipe, and both of them are larger than those of the P4 pipe. Fig. 16 shows the variation of $V_{\mathrm{p}}$ normalized by the volume of free field settlement trough at the level of pipe axis with the $E I$ of the pipe. It is seen that the normalized $V_{\mathrm{p}}$ decreases with $E I$. It is also found in Fig. 15 that the $V_{\mathrm{p}}$ values of P3 pipe (burial depth of $0.6 \mathrm{~m}$ ) are smaller than those of the P2 pipe (burial depth of $0.9 \mathrm{~m}$ ). The volume of free field settlement trough at the level of pipe axis is found to be larger that all $V_{\mathrm{p}}$ values, indicating that the volume of the settlement trough is reduced with the 

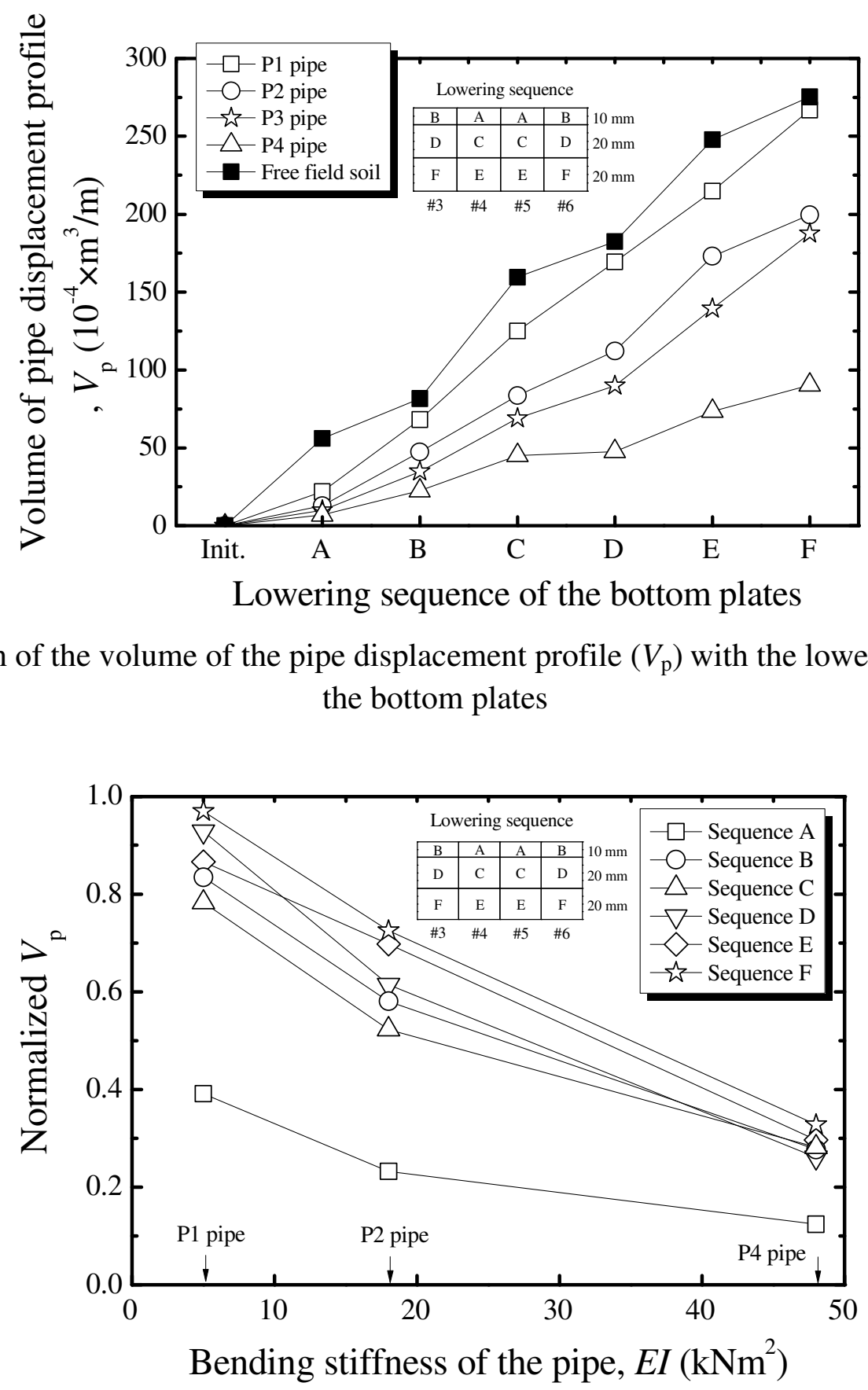

Fig. 16 Variation of normalized $V_{\mathrm{p}}$ with bending stiffness of the pipe the bottom plates

Fig. 15 Variation of the volume of the pipe displacement profile $\left(V_{\mathrm{p}}\right)$ with the lowering sequence of 
400 lowering sequence of the bottom plates. It is seen that the surface settlements of the backfill 401 measured above the P1 pipe are larger than those above the P2 pipe, and both of them are larger than 402 those above the P4 pipe, which is consistent with the vertical displacements of the pipes shown in 403 Fig. 11. The P3 pipe surface settlements are larger than the P2 pipe settlement because of the 404 difference in the vertical distance from the moveable bottom plates to the backfill surface, $0.85 \mathrm{~m}$ for 405 the P3 pipe and $1.15 \mathrm{~m}$ for the P2 pipe. Soil settlements caused by various lowering sequences of 406 bottom plates over previously consecutive sequence are also shown in Fig. 11. It is found that the 407 surface settlement of the backfill above Section 1 of the pipes increases significantly with the second, 408 fourth and sixth sequences of lowering down the bottom plates \#3 and \#6 (represented by B, D and 409 F). In contrast, only slight increases in the surface settlement are found above Sections 2 and 3 of the 410 pipes when the bottom plates \#3 and \#6 are lowered down.

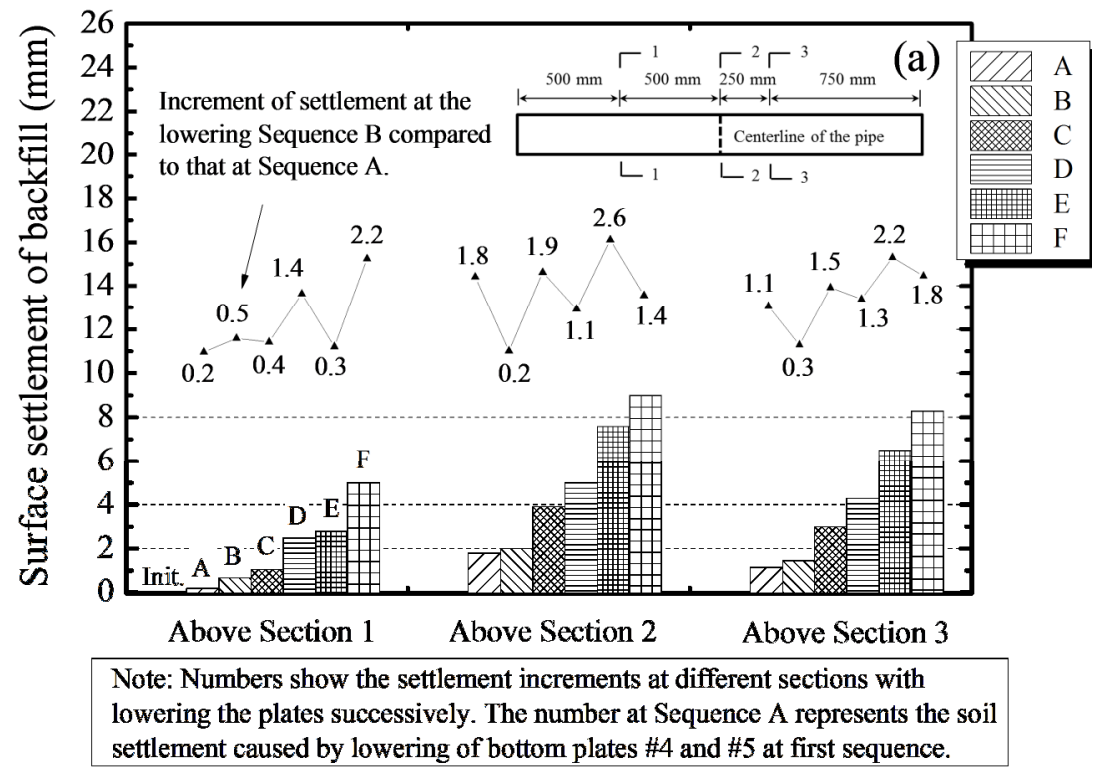


Disdance to the centerline of the model box (mm)
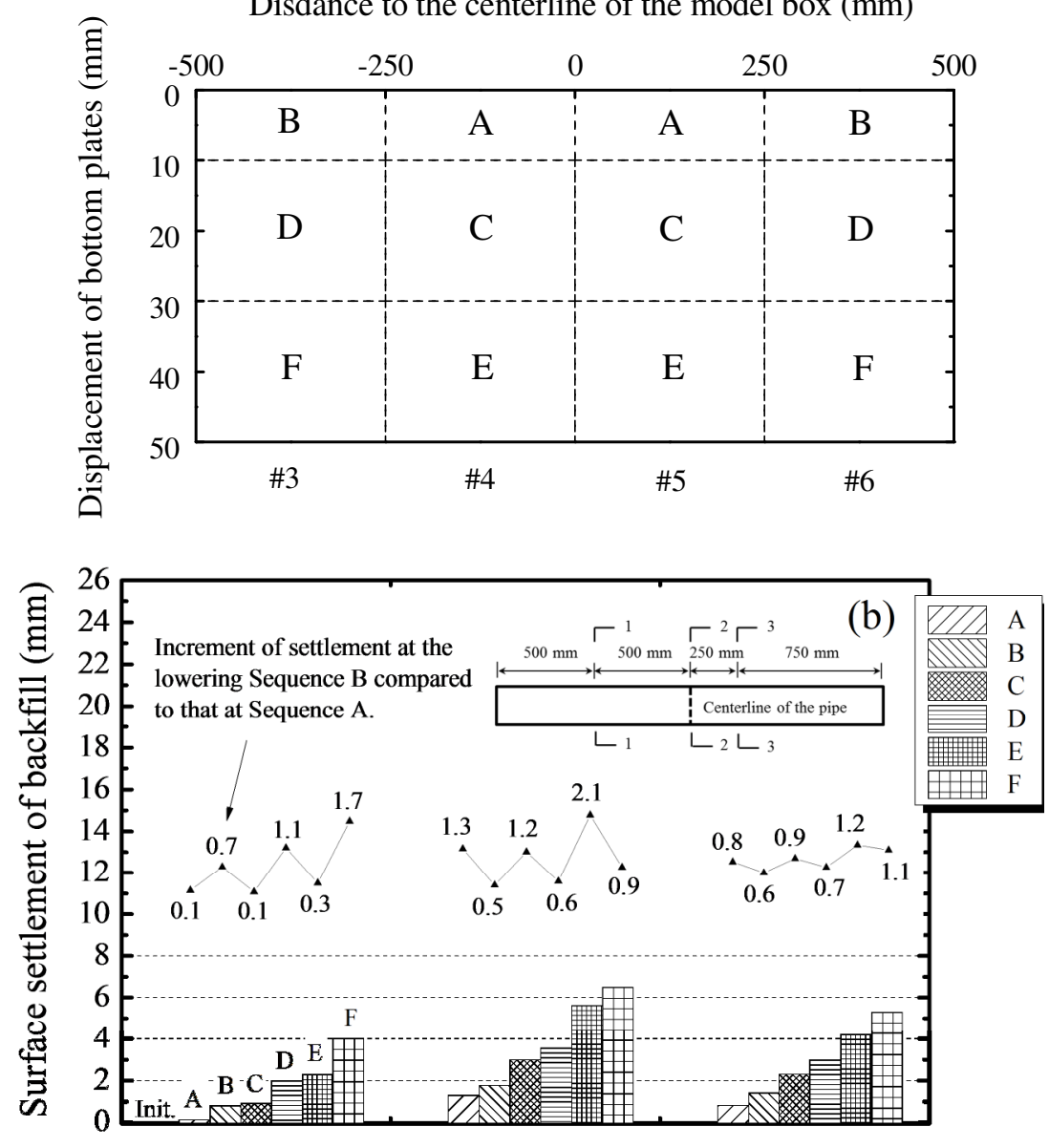

Above Section $1 \quad$ Above Section 2 Above Section 3

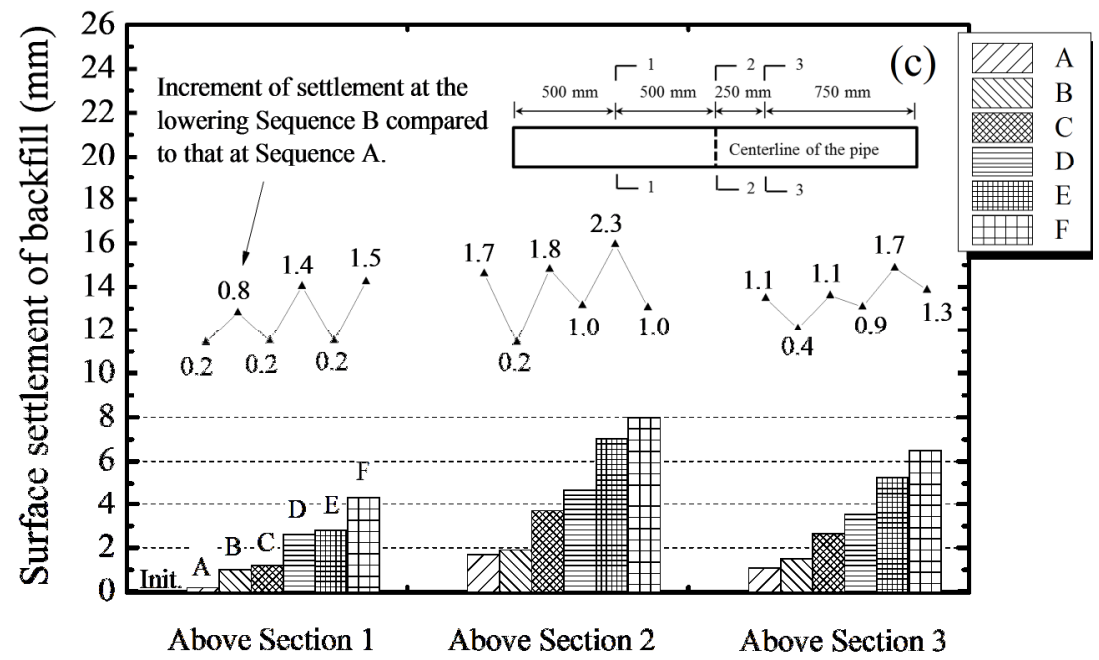




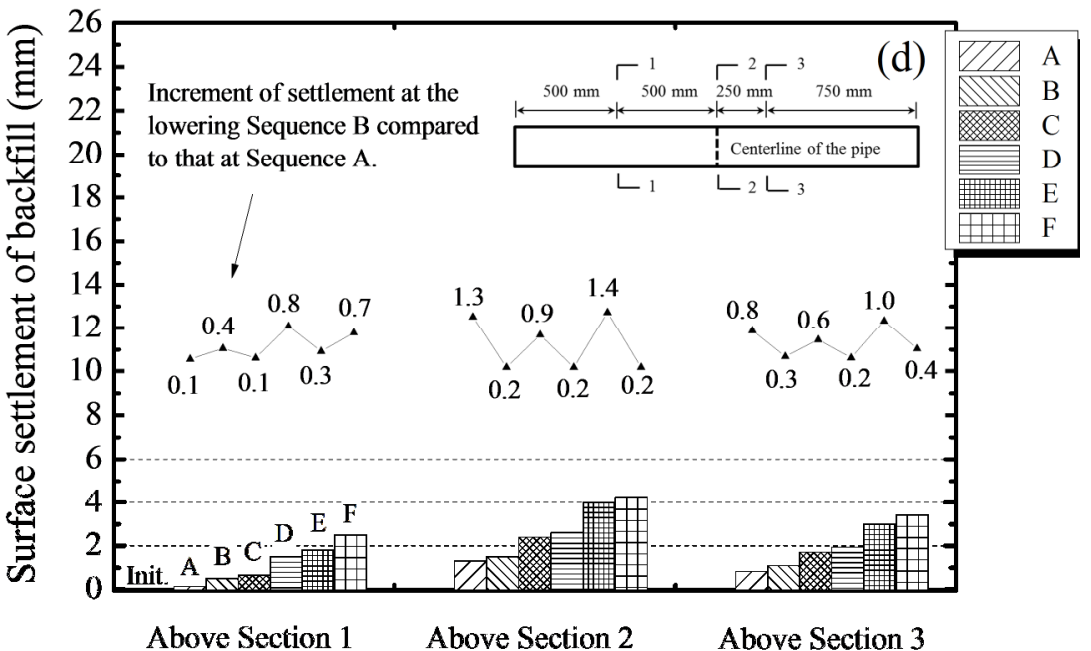

Fig. 17 Variation of the surface settlement of backfill with the lowering sequence of the bottom plates: (a) P1 pipe; (b) P2 pipe, (c) P3 pipe and (d) P4 pipe

\subsection{Earth pressure}

Figure 18 shows the variations of the earth pressures at the top of the P1, P2, P3 and P4 pipes with lowering sequence of the bottom plates. It is seen that the earth pressures measured at the pipe top at Sections 1 and 2 increase with the sequence of lowering the bottom plates. The earth pressures measured at the pipe top at Section 1 increase more significantly with lowering the bottom plates \#4 and \#5 at the first, third and fifth sequences (represented as A, C and E in Fig. 16) than those at Section 2. However, the earth pressures at the pipe top at Section 2 exhibit larger increment than those at Section 1 when lowering the bottom plates \#3 and \#6 at the sequences of second, fourth and sixth (represented as B, D and F). It is also found from Figure $\mathbf{1 8}$ (d) that the earth pressures at the bottom of Sections 1 and 2 of the P4 pipe reduce to zero when the bottom plates are lowered down for the first time, indicating that the pipe-soil separation occurs at the bottom of the pipe. It is noted that the earth pressure cells are only installed underneath the P4 pipe. 

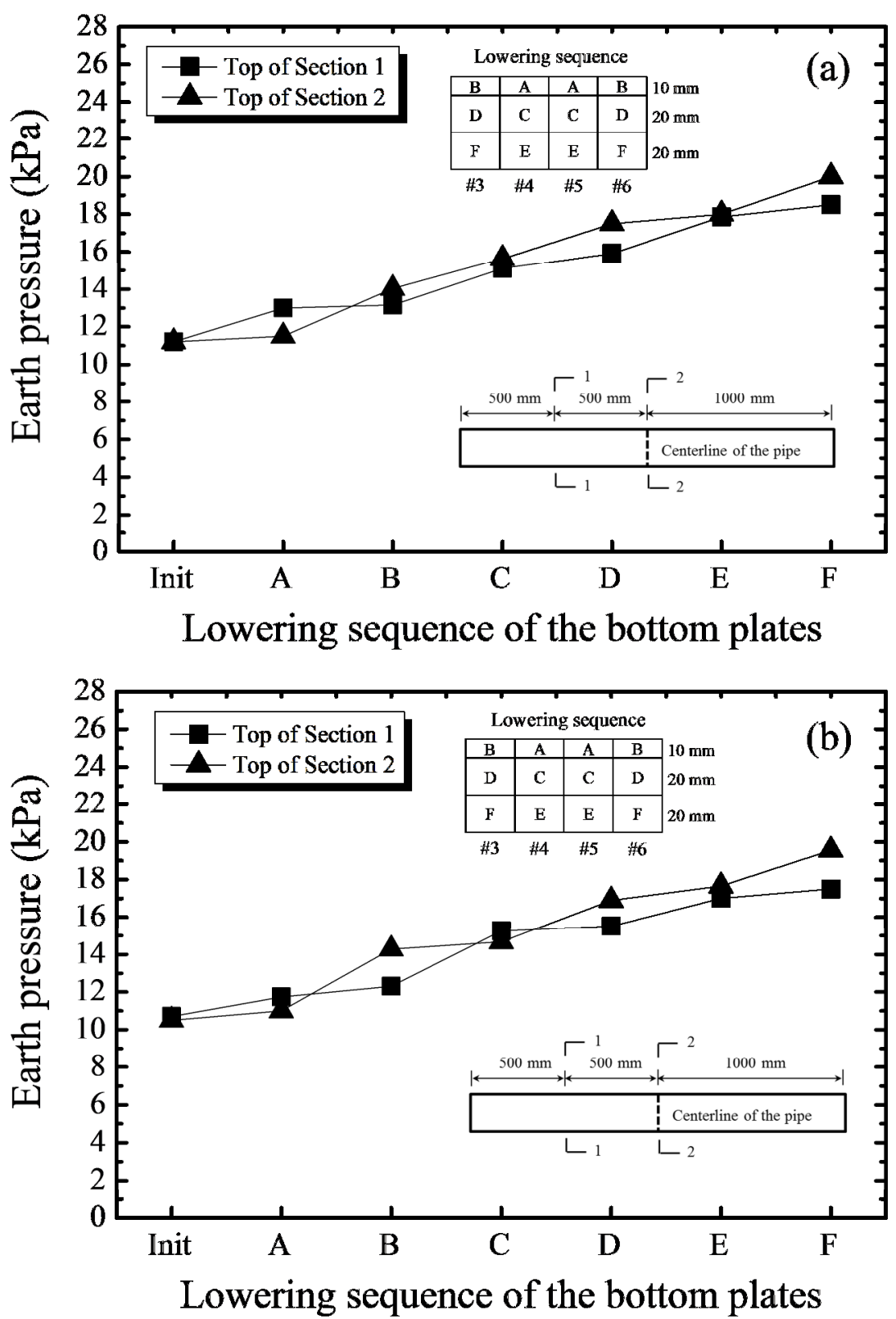

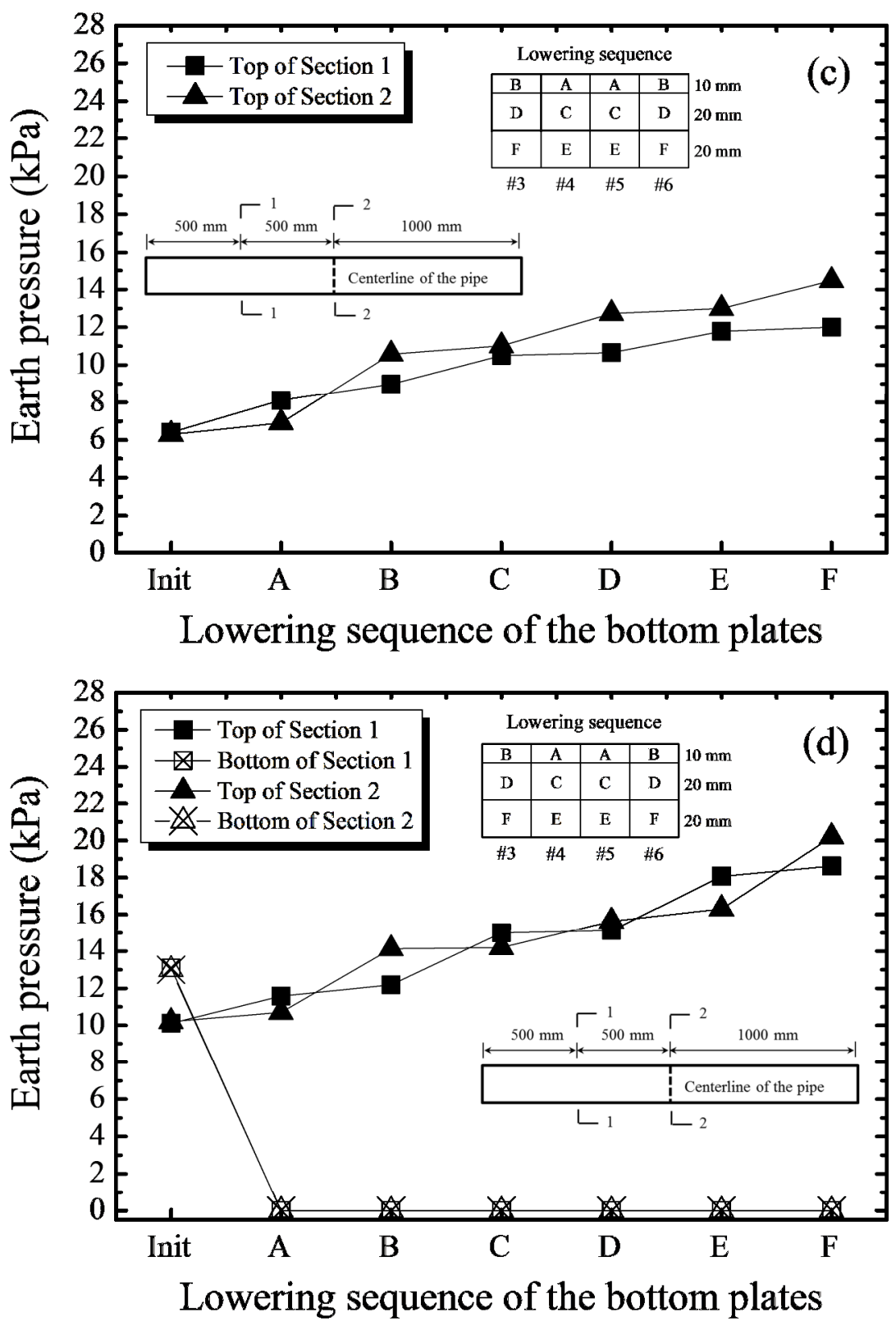

Fig. 18 Variation of measured earth pressures with the lowering sequence of the bottom plates: (a) P1 pipe; (b) P2 pipe; (c) P3 pipe; and (d) P4 pipe

\subsection{Vertical arching factor}

Vertical Arching Factor $(V A F)$ at the top of the pipe is calculated by:

$$
V A F=P / \gamma H^{\prime}
$$

where $P$ is the earth pressure at the top of the pipe $(\mathrm{kPa}) ; \gamma$ is the unit weight of the backfill $\left(\mathrm{kN} / \mathrm{m}^{3}\right)$; and $H^{\prime}$ is the soil cover thickness (m). VAF larger than one indicates that the negative soil arching is 
446 triggered at the pipe top.

$447 \quad$ Figure 19 shows the variation of $V A F$ calculated at the top of the P1, P2, P3 and P4 pipes with 448 the volume of the pipe displacement profile. It is seen from Fig. 19 (a) that the values of $V A F$ at the 449 top of the P1 pipe at Sections 1 and 2 are smaller than those of the P2 pipe, and both are smaller than 450 those at the top of the P4 pipe at different lowering sequences of the bottom plates. Fig. 19(b) shows 451 that the values of VAF at the top of the P2 pipe at Sections 1 and 2 are smaller than those of the P3 452 pipe. It is concluded that negative soil arching effect at the top of the pipe increases with bending 453 stiffness but decreases with burial depth during localized ground subsidence. AASHTO (2012) 454 recommends the following equation to calculate the $V A F$ at the top of buried flexible pipes:

$$
V A F=0.76-0.71\left(S_{\mathrm{H}^{-}}-1.17\right) /\left(S_{\mathrm{H}}+2.92\right)
$$

$$
S_{\mathrm{H}}=\varphi^{\prime} M_{\mathrm{s}} R / E A
$$

457 where $S_{H}$ is the hoop stiffness factor; $\varphi^{\prime}$ is the resistance factor for soil stiffness (taken as 0.9 ); $M_{\mathrm{s}}$ is 458 the constrained soil modulus $(\mathrm{kPa}) ; R$ is the radius from center of pipe to centroid of pipe profile $(\mathrm{m})$; $459 E$ is the elastic modulus of pipe material $(\mathrm{kPa})$; and $A$ is the gross area of pipe wall per unit length of 460 pipe $\left(\mathrm{m}^{2} / \mathrm{m}\right)$. 

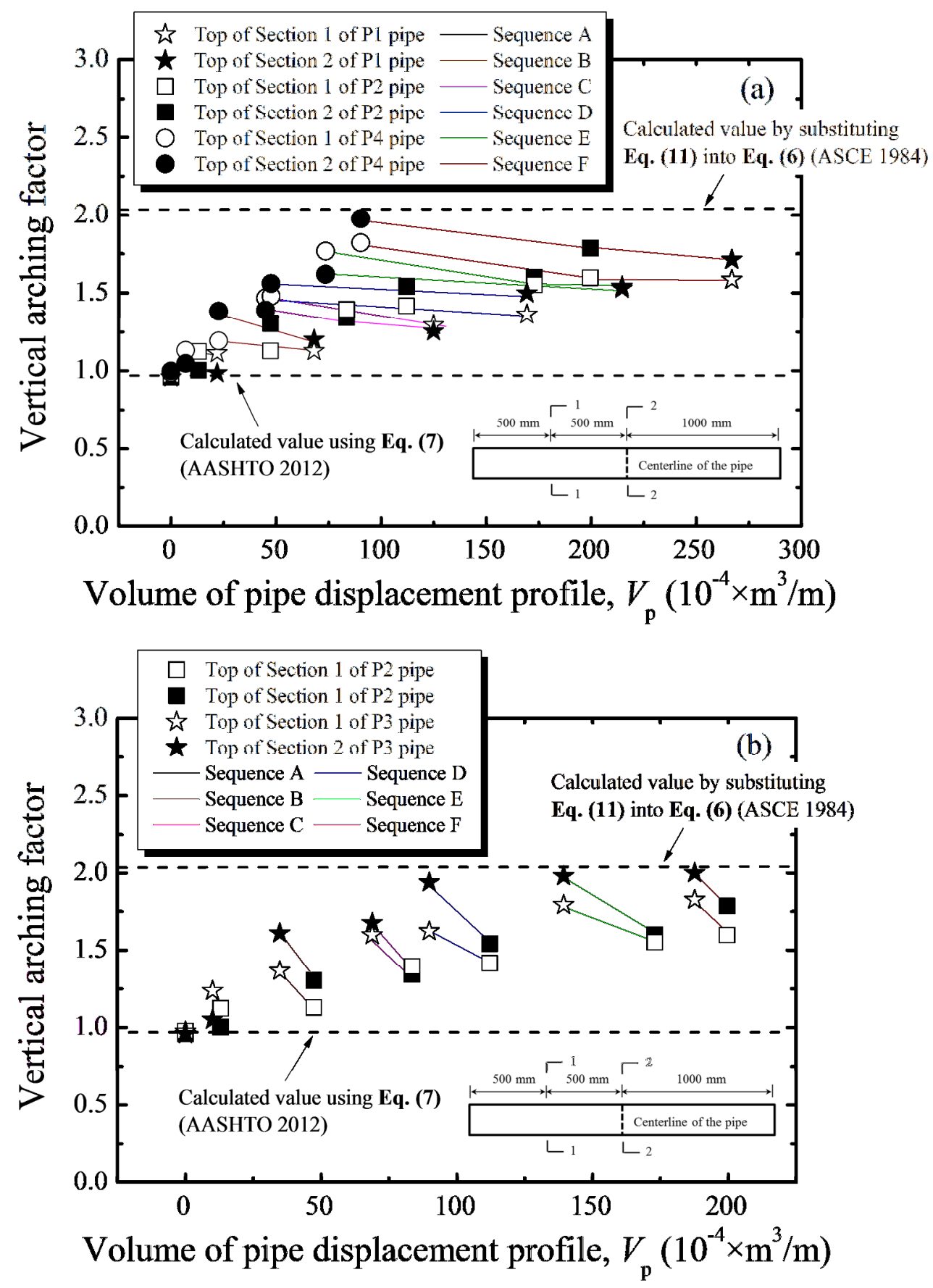

US Committee on Gas and Liquid Fuel Lifelines suggests the following equation to calculate

$$
q_{\mathrm{u}}=N_{\mathrm{v}} \gamma H D
$$


where $q_{\mathrm{u}}$ is the maximum resistance force $(\mathrm{kN} / \mathrm{m}) ; N_{\mathrm{v}}$ is a dimensionless factor; $\gamma$ is the unit weight of the soil $\left(\mathrm{kN} / \mathrm{m}^{3}\right) ; H$ is the burial depth to the axis of the pipe $(\mathrm{m}) ; D$ is the diameter of the pipe (m); and $\varphi$ is the internal friction angle of the soil $\left(^{\circ}\right)$.

The earth pressure at the top of the pipe can be calculated by:

$$
P=q_{\mathrm{u}} / D
$$

Substituting Eq. (11) into Eq. (6) gives the value of $V A F$.

It is seen from Fig. 19 that the values of $V A F$ calculated by Eq. (7) agree well with those measured at the top of the pipes when the backfilling process is completed (i.e., the volume of pipe displacement is zero). However, the calculated values by Eq. (7) are $13 \%$ to $54 \%$ smaller than the measured when the bottom plates are lowered down. The parameters used in Eqs. (7) and (8) are listed in Table 4. For the determination of $A$ value of the pipe wall, double-wall corrugated pipe is idealized as plate elements as per AASHTO (2012). Geometric property (i.e. the $A$ ) is determined by the integration of the areas of the corrugations. The elastic modulus of the pipe $(E)$ is taken as 520 $\mathrm{MPa}$, representing a secant modulus for one hour, the duration of the model test, based on the time dependent power law model developed by Chua (1986). It is indicated that AASHTO (2012)'s method underestimates $V A F$ at the top of buried pipes when the ground subsidence occurs. The values of VAF calculated by substituting Eq. (11) into Eq. (6) are 10\% and 120\% larger than the measured ones. The parameters used in Eqs. (9) to (11) are listed in Table 5. It is indicated that ASCE (1984) provides a conservative method for the calculation of earth pressure at the top of the flexible pipe subjected to the ground subsidence. This observation is consistent with that reported by Xie et al. (2013) and Saiyar et al. (2016). The reason is that the equations outlined by ASCE (1984) are based on the data from the tests on the rigid pipe, but the resistance force on the pipe increases 
494

Table 4 Parameters used in AASHTO (2012)'s method

\begin{tabular}{cccc}
\hline Pipe ID & $M_{s}(\mathrm{MPa})$ & $R(\mathrm{~m})$ & $E A(\mathrm{kN} / \mathrm{m})$ \\
\hline P1 & 3.52 & 0.105 & 2000 \\
P2 & 3.52 & 0.157 & 3000 \\
P3 & 3.52 & 0.157 & 3000 \\
P4 & 3.52 & 0.213 & 3500 \\
\hline
\end{tabular}

Table 5 Parameters used in the method outlined by ASCE (1984)

\begin{tabular}{cccc}
\hline$\gamma\left(\mathrm{kN} / \mathrm{m}^{3}\right)$ & $H(\mathrm{~m})$ & $D(\mathrm{~m})$ & $\varphi\left(^{\circ}\right)$ \\
\hline 14.6 & 0.9 & 0.4 & 32.5 \\
\hline
\end{tabular}

\section{Discussion}

It is seen from Fig. 6 that when the bottom plates \#3 and \#6 were lowered at Sequence F (i.e., the movable base is $1 \mathrm{~m}$ wide), the soil settlement at depth of $0.9 \mathrm{~m}$ at $50 \mathrm{~mm}$ from side wall of the model box is zero, which means the soil settlement range at pipe axial level (i.e., depth of $0.9 \mathrm{~m}$ ) is less than $1.9 \mathrm{~m}$ wide. Two fixing-ed frames are used to connect the ends of HDPE pipes with the wall of the model box, and a pipe plug mounted on the fixing frame is pushed into the pipe end to $\underline{\text { simulate a spigot joint. In other words, the vertical displacement of pipe segments adjacent to the test }}$ one connected by spigot joints is assumed to be zero in this study. This assumption is considered $\underline{\text { reasonable because the measured soil settlement range shown in Fig. } 6 \text { is less than } 1.9 \mathrm{~m} \text { at pipe axial }}$ level (i.e., depth of $0.9 \mathrm{~m}$ ). In the case that the test pipe longer than $2 \mathrm{~m}$ is used and the movable base is still $1 \mathrm{~m}$ wide, the vertical displacement profile of the pipe should be the same with the test results presented in this study. This is because the propagation of subsidence to the pipe is only dependent on the width of movable base, and the ranges of soil settlement at the pipe axial level in two cases 
Figure 12 shows that the maximum vertical displacements of the P1, P2, P3 and P4 pipes are

514 smaller than the maximum free field settlement at the level of pipe axis. It can be concluded that the 515 pipe deformation caused by the ground subsidence would be overestimated when the free field 516 settlement trough is used. The occurrence of the pipe-soil separation is confirmed from the 517 observation that the earth pressures at the bottom of Sections 1 and 2 of the $\mathrm{P} 4$ pipe from $13 \mathrm{kPa}$ are 518 reduced to zero with lowering of the bottom plates, as shown in Fig. 18 (d)

Fig. 18 shows that the earth pressures at the top of the pipes at Sections 1 and 2 are elevated when the bottom plates are lowered down. This is because the settlement of the backfill above the pipe (i.e., Zone B shown in Fig. 20 (a)) is smaller than that of its adjacent areas (i.e., Zones A and C) in the transverse direction of the pipe, although the relevant data are not measured in this study. As a result, negative soil arching is triggered at the top of the pipe. More load is transferred to Zone B. It 524 is also found that the earth pressures at the pipe top at Section 1 increase significantly when the bottom plates \#4 and \#5 are lowering down, while those at the pipe top at Section 2 exhibit a slight increment. This is because the incremental settlements of the backfill above Section 1 of the pipe (i.e., Zone A' shown in Fig. 20 (b)) are smaller than those above Section 2 of the pipe (i.e., Zone B') when the bottom plates \#4 and \#5 are lowered down (See Fig. 17). Consequently, more soil load is transferred from Section 2 to Section 1. It is seen from Figure 19 (a and $\mathbf{b}$ ) that $V A F$ at the pipe top at Sections 1 and 2 are not the same (the differences between two cases are $10 \%$ to $21 \%$ ) with lowering the bottom plates at different sequences. It is thus concluded that the load increment at the pipe top due to localized ground subsidence should be analyzed using a three-dimensional soil arching theory (i.e., soil arching effects in both transverse and longitudinal directions of the pipe). A 
534 study of the effect of localized ground subsidence with the consideration of 3D soil arching will be 535 future research topic.
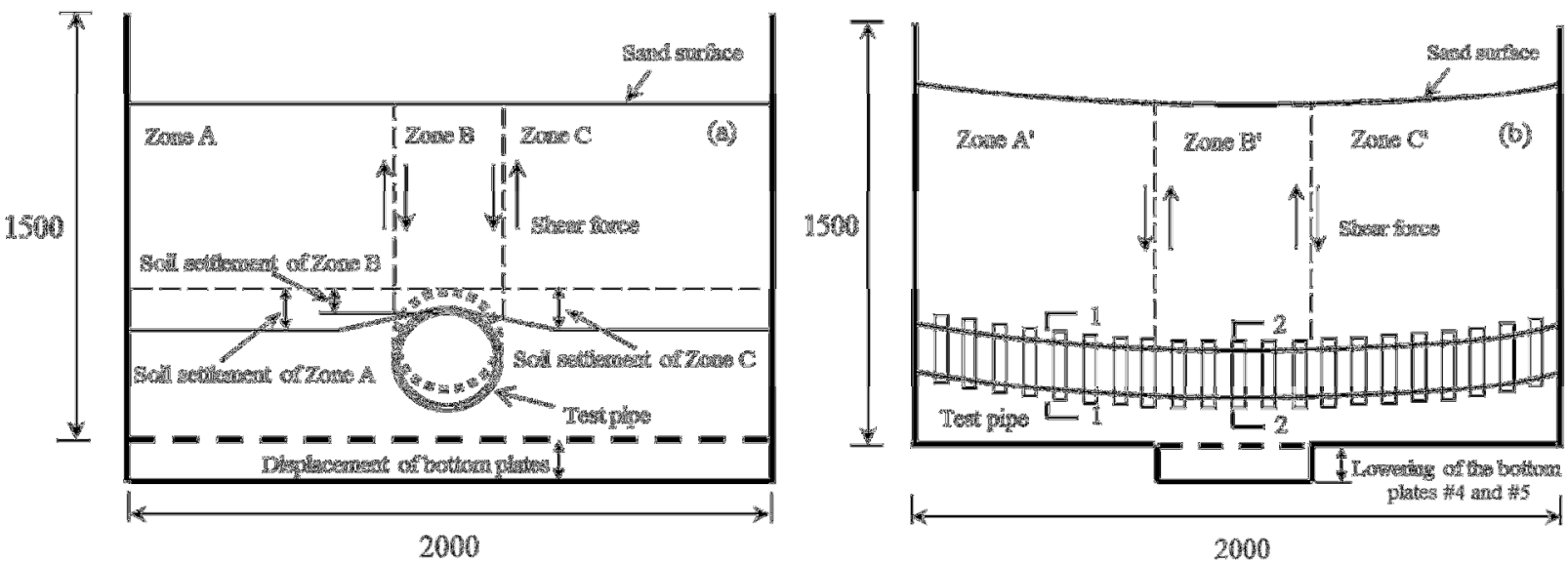

Fig. 20 Settlement of the backfill in: (a) the transverse direction and (b) the longitudinal direction of the pipe (unit: $\mathrm{mm}$ )

A linear regression method is used to correlate the volume of pipe displacement profile with the linear equation for the P1, P2, P3 and P4 pipes are 3.1, 2.8, 2.1 and 1.6, respectively. It is seen from

Fig. 21 (b) that the gradients of the linear equation decrease with $E I$ of the pipe, but increases with the burial depth. It is seen that if the magnitude of the surface settlement is same, the pipes with larger $E I$ or shallower burial depth are expected to have less deformation. Considering the difficulty in the measurement of pipe responses to the ground subsidence, Fig. 21 may provide a preliminary method for estimating the deformation of the pipe responding to the ground subsidence. The effect of ground water on the pipe-soil interaction under the localized ground subsidence will be addressed in 550 the further study. 


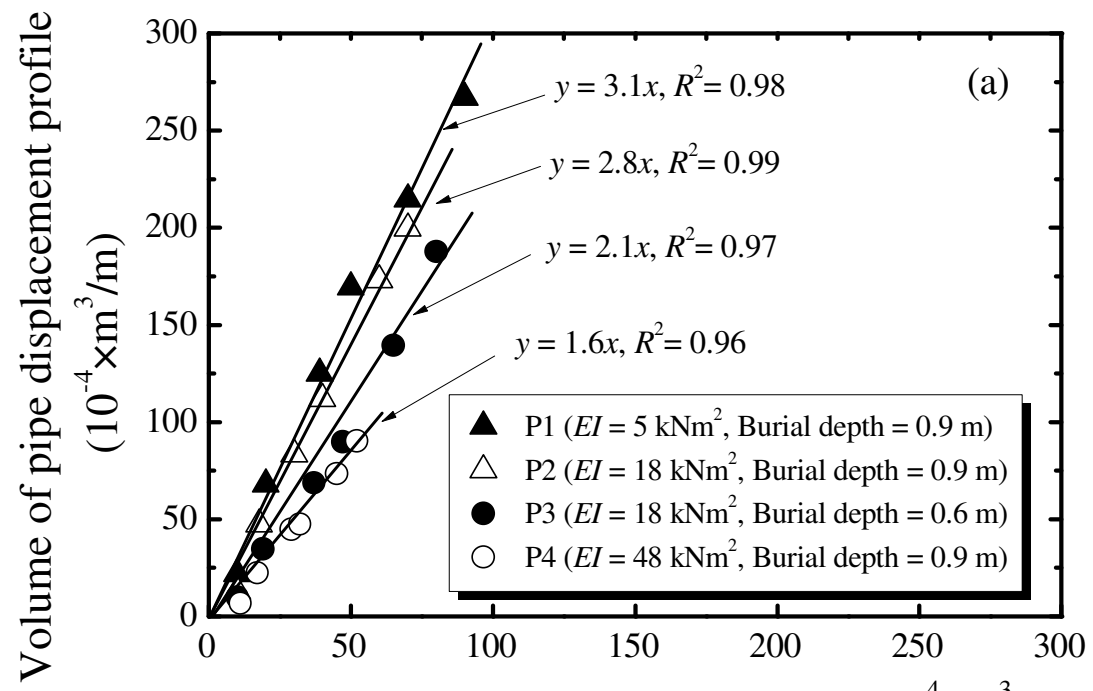

Volume of surface settlement trough $\left(10^{-4} \times \mathrm{m}^{3} / \mathrm{m}\right)$

Burial depth of the pipe $(\mathrm{m})$

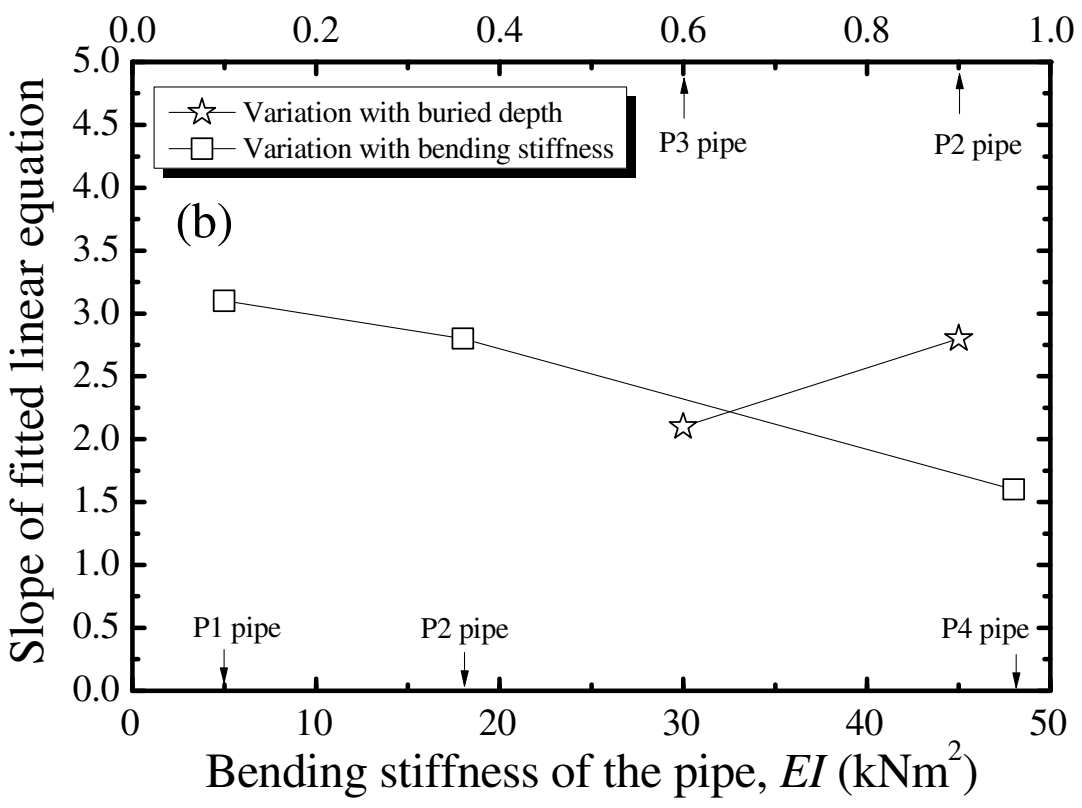

Fig. 21 Relationship of the volume of pipe displacement profile and the volume of surface settlement trough

\section{Conclusions}

A series of large scale model tests are carried out to investigate the performance of HDPE double-wall corrugated pipes subjected to localized ground subsidence. The variation of earth pressures, the vertical displacements of the pipe, and the settlements of the backfill at different depths for localized ground subsidence are investigated. Based on this study, the following 
conclusions are drawn:

(1) The trough width parameter for the free field soil $\left(i_{\text {soil }}\right)$ decreases with the depth. It is seen 564 that the soil settlement tends to spread to a wider range when it propagates towards the surface of the backfill. However, both the maximum soil settlement $\left(S_{\max }\right)$ and volume of the settlement trough $\left(V_{\text {soil }}\right)$ decrease with the depth.

(2) The maximum displacement of the pipe $\left(S_{\mathrm{pmax}}\right)$ caused by the ground subsidence is smaller than that for the free field soil (i.e., without pipe) at the level of pipe axis. Thus the pipe responses to the ground subsidence will be overestimated by using the free field settlement data.

(3) The earth pressure at the bottom of the P4 pipe reduces to zero with lowering the bottom plate. This confirms the occurrence of the pipe-soil separation. Therefore, theory of beams on 572 Winkler elastic foundation is not applicable for the structural responses of buried pipes subjected to ground subsidence, which requires a fully contact condition of soil and structure.

(4) The methods outlined by AASHTO (2012) and ASCE (1984) provide lower and upper bounds for the earth pressure at the top of the HDPE pipes subjected to the ground subsidence, respectively. Variation of the earth pressure at the pipe top due to localized ground subsidence should be analyzed with a three-dimensional soil arching theory.

(5) Linear equations are established to correlate the volume of pipe displacement profile with the volume of settlement trough at the backfill surface. For the four cases studied, the values for the result in less pipe deformation. 


\section{Acknowledgements}

The authors are grateful for the financial support of the National Natural Science Foundation of 587 China (Grant Nos. 51108078 and 41472258), Natural Science Foundation of Jiangsu Province (Grant 588 Nos. BK20131294 and BK2012022), and the Fundamental Research Funds for the Central 589 Universities, Colleges and Universities in Jiangsu Province Plans to Graduate Research and 590 Innovation (Grant No. KYLX_0144), and the Scientific Research Foundation of Graduate School of 591 Southeast University (Grant No. YBJJ1632).

593 Notations:

594 Basic SI units are given in parentheses.

$595 A$ : gross area of pipe wall per unit length of pipe $\left(\mathrm{m}^{2} / \mathrm{m}\right)$

$596 \quad D$ : diameter of the pipe (m)

$597 \quad E$ : elastic modulus of pipe material $(\mathrm{kPa})$

$598 \quad H$ : burial depth to the axis of the pipe (m)

$599 \quad H^{\prime}$ : soil cover thickness (m)

$600 i$ : trough width parameter corresponding to the distance from the centerline of the subsidence trough 601 to the point of inflection (m)

$602 i_{\text {soil }}$ : trough width parameter of settlement profile at the free field soil $(\mathrm{m})$

$603 i_{\mathrm{p}}$ : trough width parameter of pipe displacement profile $(\mathrm{m})$

$604 m$ : parameter to ensure $S_{\max }$ remain the maximum soil settlement

$605 M_{s}$ : constrained soil modulus $(\mathrm{kPa})$ 
$606 n$ : parameter to ensure $i$ remain the distance from the centerline of the subsidence trough to the 607 inflection point

$608 \quad N_{\mathrm{v}}$ : dimensionless factor

$609 P$ : earth pressure at the top of the pipe $(\mathrm{kPa})$

$610 q_{\mathrm{u}}$ : maximum resistance force $(\mathrm{kN} / \mathrm{m})$

$611 R$ : radius from center of pipe to centroid of pipe profile (m)

$612 S_{H}$ : hoop stiffness factor

$613 S_{\max }$ : maximum settlement of the free field soil $(\mathrm{m})$

$614 S_{\text {pmax }}:$ maximum vertical displacement of the pipe (m)

$615 V A F$ : vertical arching factor

$616 V_{\text {soil }}$ : volume of the free field settlement trough at the level of pipe axis $\left(\mathrm{m}^{3}\right)$

$617 V_{\mathrm{p}}$ : volume of the pipe displacement profile $\left(\mathrm{m}^{3}\right)$

$618 x$ : distance to the centerline of the ground subsidence zone $(\mathrm{m})$

619 Z: depth of settlement plates (m)

$620 \alpha$ : parameter influencing the shape of the curve

$621 \gamma$ : unit weight of the backfill $\left(\mathrm{kN} / \mathrm{m}^{3}\right)$

$622 \varphi$ : is the internal friction angle of the soil $\left({ }^{\circ}\right)$

$623 \varphi^{\prime}$ : resistance factor for soil stiffness

625 Abbreviations

626 AASHTO American Association of State Highway and Transportation Officials

627 ASCE American Society of Civil Engineers 


\section{References}

American Association of State Highway and Transportation Officials (AASHTO). 2012. AASHTO LRFD bridge design specifications (second edition). Sec. 12, Washington, D. C.

Almahakeri, M., Fam, A., \& Moore, I.D. 2012. Longitudinal bending and failure of GFRP pipes buried in dense sand under relative ground movement. Journal of Composites for Construction 17(5): 702-710.

American Lifelines Alliance (ALA). 2005. Guidelines for the design of buried steel pipe (with addenda through February 2005), American Society of Civil Engineers, New York, 76p.

Anderson, C., Wijewickreme, D., Ventura, C., \& Mitchell, A. 2005. Full-scale laboratory testing of pipe-soil interaction in branched polyethylene pipelines. Experimental Techniques 29(2): 33-37.

ASCE. 1984. Guidelines for the seismic design of oil and gas pipeline systems. Committee on Gas and Liquid Fuel Lifelines. American Society of Civil Engineers, New York, 473p.

ASTM. 2014. Standard Test Methods for Specific Gravity of Soil Solids by Water Pycnometer-D854-14, Annual Book of ASTM Standards, ASTM International, West Conshohocken, Pa.

ASTM. 2011. Standard practice for classification of soils for engineering purpose-D2487-11, Annual Book of ASTM Standards, ASTM International, West Conshohocken, Pa.

ASTM. 2011. Standard Test Method for Direct Shear Test of Soils Under Consolidated Drained Conditions-D3080-11, Annual Book of ASTM Standards, ASTM International, West 
Conshohocken, Pa.

ASTM. 2014. Standard Test Methods for Maximum Index Density and Unit Weight of Soils Using a Vibratory Table-D4253-14, Annual Book of ASTM Standards, ASTM International, West Conshohocken, Pa.

ASTM. 2011. Standard Test Methods for One-Dimensional Consolidation Properties of Soils Using Incremental Loading-D2435/D2435M-11, Annual Book of ASTM Standards, ASTM International, West Conshohocken, Pa.

Attewell, P. B. \& Farmer, I. W. 1974. Ground deformations resulting from shield tunneling in London clay. Canadian Geotechnical Journal, Vol. 11, No. 3, pp. 380-395, DOI: 10.1139/t74-039.

Attewell, P. B., Yeates, J., \& Selby, A. R. 1986. Soil movements induced by tunneling and their effects on pipelines and structures, Blackie and Son Ltd., London.

Balkaya, M., Moore, I.D., \& Sağlamer, A. 2012. Study of Nonuniform Bedding Support Because of Erosion under Cast Iron Water Distribution Pipes. Journal of Geotechnical \& Geoenvironmental Engineering 138(10): 1247-1256.

Bransby, M.F., EL Nahas, A., Turner, E., \& Davies, M.C.R. 2007. The interaction of reverse faults with flexible continuous pipelines. International Journal of Physical Modelling in Geotechnics 7(3): $25-40$.

Celestino, T B, Gomes, R, \& Bortolucci, A A. 2000. Errors in ground distortions due to settlement trough adjustment. Tunnelling and Underground Space Technology, 15(1): 97-100.

Chan, P.D.S., \& Wong, R.C.K. 2004. Performance evaluation of a buried steel pipe in a movingslope: a case study. Canadian Geotechnical Journal 41(5): 894-907.

Choo, Y.W., Abdoun, T.H., O'Rourke, M.J., \& Ha, D. 2007. Remediation for buried pipeline systems 
under permanent ground deformation. Soil Dynamics and Earthquake Engineering 27(12): 1043-1055.

Chua, K. M. 1986. Time-dependent interaction of soil and flexible pipe. Ph.D. thesis, Texas A \& M University, College Station, Tex.

Daiyan, N., Kenny, S., Phillips, R., \& Popescu, R. 2011. Investigating pipeline-soil interaction under axial-lateral relative movements in sand. Canadian Geotechnical Journal 48(11): 1683-1695.

Dhar, A. S., Moore, I. D., \& McGrath, T. J. 2004. Two-dimensional analyses of thermoplastic culvert deformations and strains. Journal of geotechnical and geoenvironmental engineering, 130(2), 199-208.

Duan, G.j. 2002. Study on the settlement at ground surface due to tunneling and its effects on the pipeline behaviors. Ph.D. thesis, China University of Geoscience, Beijing, China (in Chinese).

Gantes, C.J., \& Bouckovalas, G. 2013. Seismic verification of the high pressure natural gas pipeline komotini-alexandroupoulis-kipi in areas of active fault crossings. Structural Engineering International 23(2): 204-208.

Hachiya, M., Inoue, Y., Tohda, J., Takatsuka, Y., \& Takagi, R. 2002. Response of buried pipelines subjected to differential ground settlement. Physical Modelling in Geotechnics: ICPMG'02, 911-916.

Han, J., Wang, F., Khatri, D., Parsons, R., \& Brennan, J. 2015. Establishing a design procedure for buried steel-reinforced high-density polyethylene pipes: a field study. Final Report submitted to Kansas Department of Transportation, K-TRAN: KU14-4, Lawrence, USA.

Han, J., Acharya, R., Parsons, R., \& Khatri, D. 2013. Improved load distribution for load rating of low-fill box structures. Final Report submitted to Kansas Department of Transportation, 
JGWA. 1982. Recommended Practices for Earthquake resistant design for gas pipelines. Japanese Gas Works Association.

Jiang M. \& Yin Z.Y. 2012. Analysis of stress redistribution in soil and earth pressure on tunnel lining

by discrete element method. Tunnelling and Underground Space Technology 32: 251-259.

Jiang M. \& Yin Z.Y. 2014 Influence of soil conditioning on ground deformation during longitudinal tunneling. Comptes Rendus Mecanique 342(3): 189-197.

Karamitros, D.K., Bouckovalas, G.D., \& Kouretzis, G.P. 2007. Stress analysis of buried steel pipelines at strike-slip fault crossings. Soil Dynamics and Earthquake Engineering 27(3): 200-211.

Karamitros, D.K., Bouckovalas, G.D., Kouretzis, G.P., \& Gkesouli, V. 2011. An analytical method for strength verification of buried steel pipelines at normal fault crossings. Soil Dynamics and Earthquake Engineering 31(11): 1452-1464.

Kennedy, R.P., Chow, A., \& Williamson, R. 1977. Fault movement effects on buried oil pipeline. Journal of Transportation Engineering 103(5): 617-633.

Kouretzis, G.P., Karamitros, D.K., \& Sloan, S.W. 2015. Analysis of buried pipelines subjected to ground surface settlement and heave. Canadian Geotechnical Journal 52(8): 1058-1071.

Li, H., Xue, N., Li, X., \& Li, Z. 2012. An in-situ experimental study on buried pipelines with internal pressure subject to a simulated reverse-slip fault movement. In The 15 th World Conference on Earthquake Engineering, Beijing, China (15WCEE).

Liu, X.J. \& O'Rourke, M.J. 1997. Behaviour of continuous pipeline subject to transverse PGD. Earthquake Engineering \& Structural Dynamics. 26(10): 989-1003. 
Luo, X., Lu, S., Shi, J., Li, X., \& Zheng, J. 2015. Numerical simulation of strength failure of buried polyethylene pipe under foundation settlement. Engineering Failure Analysis 48: 144-152.

Mahdavi, H., Kenny, S., Phillips, R., \& Popescu, R. 2013. Significance of geotechnical loads on local buckling response of buried pipelines with respect to conventional practice. Canadian Geotechnical Journal 50(1): 68-80.

Moore, I. D. \& Hu, F. 1996. Linear viscoelastic modelling of profiled high density polyethylene pipe. Canadian Journal of Civil Engineering, 23(2), 395-407.

Newmark, N.M., \& Hall, W.J. 1975. Pipeline design to resist large fault displacement. In U.S. National Conference on Earthquake Engineering, Ann Arbor, MI.

Ni P. 2016. Nonlinear soil-structure interaction for buried pressure pipes under differential ground motion. Ph.D. thesis, Queen's University, Kinston, Canada.

O'Rourke, T.D. 2010. Geohazards and large, geographically distributed systems. Geotechnique 60(7): $505-543$.

O'Rourke, M.J. 1989. Approximate analysis procedures for permanent ground deformation effects on buried pipelines, Proceedings of the Second U.S. Japan Workshop on Liquefaction, Large Ground Deformation and Their Effects on Lifelines, Buffalo, New York, Technical Report NCEER-89-0032, Multidisciplinary Center for Earthquake Engineering Research, Buffalo, New York, 336-347.

O'Rourke, M., Gadicherla, V., \& Abdoun, T. 2005. Centrifuge modeling of PGD response of buried pipe. Earthquake Engineering and Engineering Vibration 4(1): 69-73.

Peck, B. 1969. Deep excavations and tunneling in soft ground. Proceedings of 7 th International Conference on Soil Mechanics and Foundation Engineering. Mexico city, 1969, pp. 225-290. 
Saiyar, M. 2011. Behaviour of buried pipelines subject to normal faulting. Ph.D. thesis, Queen's University, Kingston, ON, Canada.

Saiyar, M., Ni, P., Take, W.A., \& Moore, I.D. 2016. Response of pipelines of differing flexural stiffness to normal faulting. Géotechnique 66(4): 275-286.

Shen, S.L., Cui, Q.L., Ho, E.C., \& Xu, Y.S. 2016. Ground response to multiple parallel microtunneling operations in cemented silty clay and sand. Journal of Geotechnical and Geoenvironmental Engineering 142(5): 04016001(1-11).

Shen, S.L., Wu, H.N., Cui, Y.J., \& Yin, Z.Y. 2014. Long-term settlement behavior of the metro tunnel in Shanghai. Tunneling and Underground Space Technology 40(2014): 309-323.

Shen, S.L., \& Xu, Y.S. 2011. Numerical evaluation of land subsidence induced by groundwater pumping in Shanghai. Canadian Geotechnical Journal 48(9): 1378-1392.

Shen, Y., Gao, B., Yang, X., \& Tao, S. 2014. Seismic damage mechanism and dynamic deformation characteristic analysis of mountain tunnel after Wenchuan earthquake. Engineering Geology, 180: 85-98.

Trautmann, C.H. \& T.D. O'Rourke, 1983. Behavior of Pipe in Dry Sand Under Lateral and Uplift Loading. Geotechnical Engineering Report 83-6, Cornell University, Ithaca, New York.

Trifonov, O.V., \& Cherniy, V.P. 2012. Elastoplastic stress-strain analysis of buried steel pipelines subjected to fault displacements with account for service loads. Soil Dynamics and Earthquake Engineering 33(1): 54-62.

Vorster, T. E. B. 2005. The effects of tunnelling on buried pipes. Ph.D. thesis, Cambridge University, Cambridge, UK.

Vorster, T. E. B., Klar, A., Soga, K., \& Mair, R. J. 2005. Estimating the effects of tunneling on 
existing pipelines. Journal of Geotechnical and Geoenvironmental Engineering, 131(11), $1399-1410$.

Wang, F., Du, Y. J., \& Yang, X. M. 2015. Physical modeling on ground responses to tunneling in sand considering the existence of HDPE pipes. ASTM Geotech. Test. J, 38(1), 85-97.

Wang, L.R.L., \& Yeh, Y.H. 1985. A refined seismic analysis and design of buried pipeline for fault movement. Earthquake engineering \& structural dynamics 13(1): 75-96.

Weerasekara, L., \& Wijewickreme, D. 2008. Mobilization of soil loads on buried, polyethylene natural gas pipelines subject to relative axial displacements. Canadian Geotechnical Journal 45(9): 1237-1249.

White, D., Cheuk, C., \& Bolton, M. 2008. The uplift resistance of pipes and plate anchors buried in sand. Géotechnique 58(10): 771-779.

Wu N. 2007. Application development of HDPE double-wall corrugated pipes. Plastics, 36(5), 39-42. (in Chinese)

Wu, Y.X., \& Shen, S.L., Yuan, D.J. 2016. Characteristics of dewatering induced drawdown curve under barrier effect of retaining wall in aquifer. Journal of Hydrology 539(2016): 554-566.

Xie, X., Symans, M.D., O'Rourke, M.J., Abdoun, T.H., \& O'Rourke, T.D., Palmer, M.C., and Stewart, H.E. 2013. Numerical modeling of buried HDPE pipelines subjected to normal faulting: a case study. Earthquake Spectra 29(2): 609-632.

Xu, Y.S., Ma, L., Shen, S.L., \& Sun, W.J. 2012. Evaluation of land subsidence by considering underground structures penetrated into aquifers in Shanghai. Hydrogeology Journal 20(8): $1623-1634$.

Xu, Y.S., Shen, S.L., Ren, D.J., \& Wu, H.N. 2016. Factor analysis of land subsidence in Shanghai: a 
view based on Strategic Environmental Assessment. Sustainability 8(2016): 573(1-12).

783 Yang, X., Han, J., Pokharel, S. K., Manandhar, C., Parsons, R. L., Leshchinsky, D., \& Halahmi, I. 784 2012. Accelerated pavement testing of unpaved roads with geocell-reinforced sand bases. 785 Geotextiles and Geomembranes, 32: 95-103.

786 Yin, Z.Y., Karstunen, M., Chang, C.S., Koskinen, M., \& Lojander, M. 2011. Modeling 787 time-dependent behavior of soft sensitive clay. ASCE Journal of Geotechnical and 788 Geoenvironmental Engineering 137(11): 1103-1113.

789 Yin, Z.Y. \& Chang, C.S. 2013. Stressdilatancy behavior for sand under loading and unloading 790 conditions. International Journal for Numerical and Analytical Methods in Geomechanics 37(8): 855-870.

792 Yin, Z.Y., Zhu, Q.Y., \& Zhang, D.M. 2017. Comparison of two creep degradation modeling 793 approaches for soft structured soils. Acta Geotechnica: 1-19.

794 Yoshizaki, K., O'Rourke, T.D., \& Hamada, M. 2003. Large scale experiments of buried steel 795 pipelines with elbows subjected to permanent ground deformation. Structural 796 Engineering/Earthquake Engineering 20(1): 1-11.

797 Zhou X.F. 2009. Safety technology and engineering: safety effect study on foundation settlement 798 induced by dewatering to the buried pipeline, MSC dissertation. Capital University of Economics 799 and Business; China. 
803 Table 1 Physical properties of the HDPE pipes

Table 2 Gradation characteristics of Yangtze River sand

Table 3 Summary of test cases

Table 4 Parameters used in AASHTO (2012)'s method

Table 5 Parameters used in the method outlined by ASCE (1984) 


\section{Figure captions}

Fig. 1 Schematic diagram of the model box (unit: mm) (modified from Wang et al. (2015))

Fig. 2 Relationship between the falling height and dry density of the sand

Fig. 3 settlement plate (unit: $\mathrm{mm}$; "y" depends on the distance from the monitoring point to the sand surface)

Fig. 4 Testing instrumentation: (a) P1 pipe; (b) P2 pipe, (c) P3 pipe, (d) P4 pipe and (e) free field (no pipe) (unit: $\mathrm{mm}$ )

Fig. 5 Moving patterns of the bottom plates (letters A throughout F represent the lowering sequence)

Fig. 6 Free field settlement: (a) $Z=0 \mathrm{~m}$; (b) $Z=0.3 \mathrm{~m}$; (c) $Z=0.6 \mathrm{~m}$; and (d) $Z=0.9 \mathrm{~m}$ ( $Z$ represents the initial depth of the settlement plate when the backfilling is completed)

Fig. 7 Influence of $\alpha$ on the modified Gaussian function

Fig. 8 Variation of the trough width parameter $\left(i_{\text {soil }}\right)$ with the lowering sequence of the bottom plates in free field case ("Init." represents the completion of the backfilling)

Fig. 9 Variation of the maximum soil settlement $\left(S_{\max }\right)$ with the lowering sequence of the bottom plates in free field case

Fig. 10 Variation of the volume of the settlement trough in free field case

Fig. 11 Variation of the vertical displacement of the pipe with the lowering sequence of the bottom plates: (a) P1 pipe, (b) P2 pipe, (c) P3 pipe and (d) P4 pipe

Fig. 12 Variation of the maximum vertical displacement of the pipe with the lowering sequence of the bottom plates

Fig. 13 Variation of normalized $S_{\text {pmax }}$ with bending stiffness of the pipe

Fig. 14 Variation of the trough width parameter with the lowering sequence of the bottom plates

Fig. 15 Variation of the volume of the pipe displacement trough $\left(V_{\mathrm{p}}\right)$ with the lowering sequence of the bottom plates

Fig. 16 Variation of normalized $V_{\mathrm{p}}$ with bending stiffness of the pipe 
835 Fig. 17 Variation of the surface settlement of backfill with the lowering sequence of the bottom plates:

(a) P1 pipe; (b) P2 pipe, (c) P3 pipe and (d) P4 pipe

Fig. 18 Variation of measured earth pressures with the lowering of the bottom plates: (a) P1 pipe; (b) P2 pipe, (c) P3 pipe and (d) P4 pipe

Fig. 19 Comparison of the vertical arching factor at the top of the pipes with the volume of pipe 840 displacement profile: (a) P1, P2, and P4 pipes and (b) P2 and P3 pipes

Fig. 20 Settlement of the backfill in: (a) the transverse direction and (b) the longitudinal direction of the pipe (unit: $\mathrm{mm}$ )

Fig. 21 Relationship of the volume of pipe displacement profile and the volume of surface settlement trough 